\title{
DIMENSÕES NASOFARÍNGEAS E QUEIXAS RESPIRATÓRIAS EM INDIVÍDUOS COM INSUFICIÊNCIA VELOFARÍNGEA SUBMETIDOS À CIRURGIA DE RETALHO FARÍNGEO.
}

\author{
RENATA PACIELLO YAMASHITA
}

Tese apresentada ao Hospital de Reabilitação de Anomalias Craniofaciais da Universidade de São Paulo para a obtenção do título de DOUTOR em Ciências.

Área de Concentração: Distúrbios da Comunicação Humana.

BAURU

2003 
DIMENSÕES NASOFARÍNGEAS E QUEIXAS RESPIRATÓRIAS EM INDIVÍDUOS COM INSUFICIÊNCIA VELOFARÍNGEA SUBMETIDOS À CIRURGIA DE RETALHO FARÍNGEO.

\section{RENATA PACIELLO YAMASHITA}

Orientadora: Prof ${ }^{a}$. Dr ${ }^{a}$. Inge Elly Kiemle Trindade

Tese apresentada ao Hospital de Reabilitação de Anomalias Craniofaciais da Universidade de São Paulo para a obtenção do título de DOUTOR em Ciências.

Área de Concentração: Distúrbios da Comunicação Humana.

BAURU 
R. Silvio Marchione, 3-20

Caixa Postal: 1501

17043-900 - Bauru - SP - Brasil

Telefone: (14) 235-8000

Prof. Dr. Adolpho José Melfi - Reitor da USP

Prof. Dr. José Alberto de Souza Freitas - Superintendente do HRAC-USP

Autorizo, exclusivamente para fins acadêmicos e científicos, a reprodução total ou parcial deste trabalho.

Renata Paciello Yamashita

Bauru, 7 de marco de 2003.

\begin{tabular}{|c|c|}
\hline $\mathrm{Y} 14 \mathrm{~d}$ & $\begin{array}{l}\text { Yamashita, Renata Paciello } \\
\text { Dimensões nasofaríngeas e queixas respiratórias } \\
\text { em individuos com insuficiência velofaringea } \\
\text { submetidos à cirurgia de retalho faríngeo./ } \\
\text { Renata Paciello Yamashita. Bauru, } 2003 . \\
\quad 74 \text { p.; il.; } 30 \mathrm{~cm} .\end{array}$ \\
\hline & $\begin{array}{l}\text { Tese (Doutorado - Ciências: Distúrbios da } \\
\text { Comunicação Humana) - HRAC-USP }\end{array}$ \\
\hline & Cópia revisada em 13/05/2003. \\
\hline & $\begin{array}{l}\text { Orientador: Profa. Dra. Inge Elly Kiemle Trindade. } \\
\text { Descritores: } 1 \text {.Fissura palatina 2.Rinomanometria } \\
\text { 3.Respiração. }\end{array}$ \\
\hline
\end{tabular}


Bauru - SP

$1981-1984$

Curso de Fonoaudiologia Universidade do Sagrado Coração - Bauru.

Fonoaudióloga do Setor de Fonoaudiologia e do Laboratório de Fisiologia do HRAC-USP, Bauru, SP.

$1988-1990$

Curso de Pós-Graduação em Distúrbios da Comunicação Humana, ao nivel de Mestrado, na Pontificia Universidade Católica de São Paulo.

1997

Título de Especialista em Motricidade Oral concedido pelo Conselho Federal de Fonoaudiologia.

$1998-2003$

Curso de Pós-Graduação em Ciências, área de concentração: Distúrbios da Comunicação Humana, no HRAC-USP.

Associações ACPA - American Cleft PalateCraniofacial Association. 
Dedico este trabalho aos meus filhos

Vitor

e

Lia

que me ensinaram que o amor não tem

limites... 
Ao meu querido

José Carlos

que com seu jeito simples continua sendo tão especial...

e

aos meus pais,

que nunca pouparam

esforços...

meu muito

obrigada. 
Agradeço especialmente à minha orientadora

$$
\text { Prof }^{a} . D r^{a} \text {. Inge Elly Kiemle Trindade, }
$$

que despertou em mim o interesse pela ciência e que ainda hoje, com o mesmo empenho e dedicação, me orienta na realização da pesquisa científica compromissada com nosso objetivo maior, o paciente fissurado. 
Agradeço ainda,

Ao Prof. Dr. José Alberto de Souza Freitas - Tio Gastão

Ao Prof. Dr. Alceu Sérgio Trindade Junior

Às colegas e alunas do Laboratório de Fisiologia: Adriana, Ana Claudia, Ana Paula, Chrystiane, Ester, Haline, Juliana, Kátia, Marileda, Ticiana, Trixy e Roberta

À minha amiga Silvia Helena Alvarez Piazentin-Penna

Às colegas e alunas do Setor de Fonoaudiologia: Andréa, Carolina, Cristianne, Cristina Guedes, Érica, Giselda, Giovana, Jacilene, Janaina, Lourdes, Renata, Rosana e Vera

À chefe do Setor de Fonoaudiologia Maria Cristina Zimmermann

Ao Prof. Dr. José Roberto Pereira Lauris

À Secretaria de Pós-Graduação

À Unidade de Ensino e Pesquisa (UEP)

Ao Setor de Comunicação

Aos pacientes fissurados. 
"De tudo ficaram três coisas: a certeza de que estava sempre começando, a certeza de que era preciso continuar e a certeza de que seria interrompido antes de terminar.

Fazer da interrupção um caminho novo, fazer da queda, um passo de dança, do medo, uma escada, do sonho, uma ponte, da procura, um encontro."

Fernando Pessoa 


\section{SUMÁRIO}

RESUMO …................................................................. i

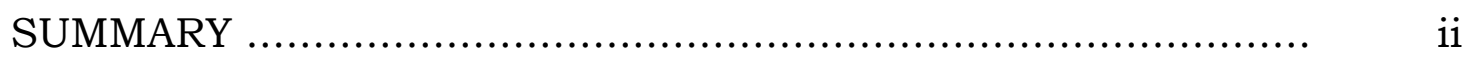

1. INTRODUÇÃO ….....................................................

2. REVISÃO DE LITERATURA ….........................................

3. OBJETIVOS …..................................................... 25

4. MATERIAL E MÉTODO ................................................... 26

4.1. População estudada ..................................................... 26

4.2. Procedimento …................................................... 30

4.2.1. Levantamento da história clínica ........................ $\quad 30$

4.2.2. Avaliação aerodinâmica da área nasal e nasofaringea 31

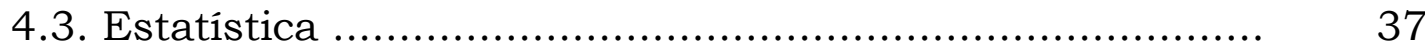

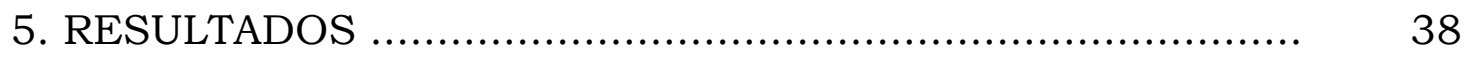

5.1. Análise das queixas respiratórias ................................ 38

5.2. Análise dos valores médios da área nasal ...................... 40

5.3. Análise dos valores individuais da área nasal ................. 44

5.4. Análise das variações individuais da área nasal .............. 47

5.5. Análise dos valores da área nasofaríngea ....................... 47

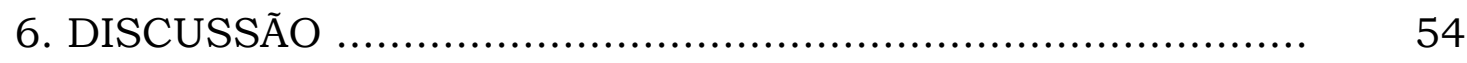

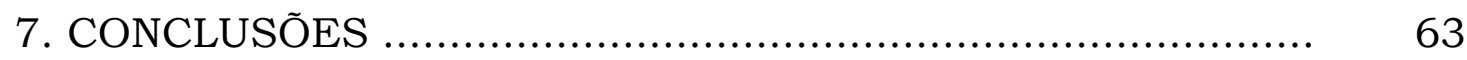

8. REFERÊNCIAS BIBLIOGRÁFICAS ...................................... 64 ANEXOS 


\section{RESUMO}

Yamashita RP. Dimensões nasofaringeas e queixas respiratórias em individuos com insuficiência velofaringea submetidos à cirurgia de retalho faringeo [Tese] Bauru: Hospital de Reabilitação de Anomalias Craniofaciais, Universidade de São Paulo; 2003.

Objetivos: Investigar o efeito da cirurgia de retalho faringeo (CRF) sobre as dimensões internas nasais de pacientes com insuficiência velofaríngea (IVF), a curto e longo prazo, e, correlacionar esses achados com o aparecimento de queixas respiratórias após a cirurgia.

Modelo/Pacientes: Estudo prospectivo em 58 pacientes com fissura palatina operada e IVF, avaliados 2 dias antes (PRE) e, 5 (POS1) e 14 meses (POS2) após a cirurgia, em média, divididos em 2 grupos: um queixas respiratórias (CQ) em POS2 e outro, sem queixas (SQ). Diferenças entre grupos e etapas foram consideradas significantes ao nível de $5 \%$.

Local: Laboratório de Fisiologia, Hospital de Reabilitação de Anomalias Craniofaciais, USP, Bauru.

Intervenções: $\mathrm{CRF}$ de pedículo superior.

Variáveis: Queixas (respiração oral, ronco e dificuldade respiratória durante o sono) e área de secção transversa mínima nasal (AN) e nasofaringea (ANF) avaliada por rinomanometria.

Resultados: Queixas respiratórias foram observadas em $55 \%$ dos pacientes em POS1 e 36\% em POS2. Observou-se na rinomanometria posterior: 1) redução significativa da AN média em POS1 e POS2, relativamente ao PRE, em ambos os grupos. Não foram observadas variações significativas na rinomanometria anterior; 2) AN média do grupo CQ significantemente menor que a do grupo SQ em POS2; 3) redução da AN mais pronunciada no grupo CQ. Medidas da ANF confirmaram esses achados.

Conclusões: A curto prazo, a CRF levou à redução significativa da dimensão nasofaríngea em proporção expressiva de pacientes, parte dos quais passaram a apresentar queixas respiratórias; a longo prazo, esse efeito atenuou-se sem, contudo, desaparecer por completo.

Descritores: retalho faríngeo, fissura palatina, respiração, técnica fluxopressão, rinomanometria. 


\section{SUMMARY}

Yamashita RP. Nasopharyngeal dimensions and respiratory complaints of individuals with velopharyngeal insufficiency submitted to pharyngeal flap surgery [Thesis] Bauru: Hospital de Reabilitação de Anomalias Craniofaciais, Universidade de São Paulo; 2003.

Objectives: To investigate the short- and long-term effect of pharyngeal flap surgery (PFS) on the internal nasal dimensions of patients with velopharyngeal insufficiency (VPI) and to correlate the findings with the onset of respiratory complaints (RC) after surgery.

Model/Patients: Prospective study in 58 patients with repaired cleft palate and VPI, evaluated, on average, 2 days before (PRE), 5 (POST1) and 14 months (POST2) after surgery, divided into 2 groups: one consisting of patients with RC (WRC) at POST2 and the other without RC (WtRC). Differences between groups and stages were considered to be significant at the $5 \%$ level.

Site: Laboratory of Physiology, Hospital for Rehabilitation of Craniofacial Anomalies, Brazil.

Interventions: Superiorly based PFS.

Variables: RC (oral respiration, snoring and respiratory difficulty during sleep), and minimal nasal (NA) and nasopharyngeal (NPA) cross-sectional area assessed by rhinomanometry.

Results: RC were observed in 55\% of patients at POST1 and 36\% at POST2. Posterior rhinomanometry showed: 1) a significant reduction of mean NA at POST1 and POST2 compared to PRE, in both groups. No significant changes were observed by anterior rhinomanometry; 2) significantly lower mean NA in the WC group compared to the WtC group at POST2; 3) more pronounced reduction in NA values in the WC group. NPA measurements confirmed these findings.

Conclusions: In the short term, PFS led to a significant reduction in the nasopharyngeal dimensions in a significant proportion of patients, part of whom started to present RC; in the long term, this effect was attenuated but did not fully disappear.

Key words: pharyngeal flap, cleft palate, respiration, pressure-flow technique, rhinomanometry. 


\section{INTRODUÇÃO.}

A fissura labiopalatina é a deformidade congênita mais comum dentre as anomalias craniofaciais e resulta da falta de fusão dos processos faciais embrionários. Anatomicamente, a fissura pode se expressar como uma fenda apenas no lábio ou acometer, isolada ou simultaneamente, o palato (Kaufman 1991). Neste último caso quase sempre vem associada a deformidades dento-esqueléticas e nasais sendo considerada a causa mais freqüente de insuficiência velofaringea (Hirschberg 1986).

As estruturas da velofaringe - palato mole e paredes laterais e posterior da faringe - desempenham papel fundamental na produção da fala, na medida em que sua ação esfinctérica é responsável pela distribuição do fluxo aéreo expiratório e das vibrações acústicas para a cavidade oral, na produção dos sons orais e para a cavidade nasal, na produção dos sons nasais. A falta do fechamento velofaríngeo - a insuficiência velofaringea - faz com que parte da corrente aérea sonorizada seja desviada para a cavidade nasal, comprometendo de diferentes formas a produção da fala. Os sintomas mais comuns da insuficiência velofaringea (IVF) são: a hipernasalidade, a emissão de ar nasal (audivel ou não) e os distúrbios articulatórios compensatórios (Hirschberg 1986, Bradley 1989, Yamashita 1990, D’Antonio 1992, Kummer et al 1992, Golding-Kushner 1995, Witzel 1995, Trindade e Trindade Junior 1996 e Zuiani et al 1998).

A cirurgia primária do palato tem como objetivo principal estabelecer condições anatômicas para o adequado fechamento velofaringeo (Brown et al 1983 e Dumbach 1987). Entretanto, em muitos casos, a cirurgia primária 
do palato não elimina os sintomas da IVF, sendo então necessária uma cirurgia secundária do palato.

Um dos procedimentos cirúrgicos empregados com mais freqüência na correção da IVF tem sido a faringoplastia de retalho faringeo. Diferentes estudos da literatura relataram elevado índice de sucesso desse tipo de cirurgia, em termos de redução ou eliminação dos sintomas de fala (Smith et al 1963, Subtelny et al 1970, Owsley Junior et al 1970, Schulz et al 1973, Leanderson et al 1974, Brondsted et al 1984, Van Demark e Hardin 1985, Hall et al 1991, Schmelzeisen et al 1992, Eufinger et al 1995, Morris et al 1995, Sloan 2000, entre outros). Entretanto, o retalho faringeo está, ao mesmo tempo, associado a um potencial significante de comprometimento das vias aéreas superiores, podendo levar à hiponasalidade, à obstrução nasal crônica, ao ronco e, à apnéia obstrutiva do sono, que podem trazer conseqüências graves aos pacientes (Bzoch 1964, Thurston et al 1980, Kravath et al 1980, Orr et al1987, Velasco et al 1988, Pensler e Reich 1991, Caouette-Laberge et al 1992, Ysunza et al 1993, Sirois et al 1994, Valnicek et al 1994, Lesavoy et al 1996, Zuiani et al 1998, Wells et al 1999, De Serres et al 1999, Peña 2000 e Liao et al 2002). Como a fissura determina deformidades nasais que, com freqüência, reduzem as dimensões da cavidade nasal (Warren et al 1992) e, por conseqüência, aumentam a resistência nasal ao fluxo aéreo respiratório, é possivel que nestes pacientes a colocação de um retalho na região da velofaringe seja um fator a mais a comprometer a permeabilidade nasal (Warren et al 1974).

A avaliação da permeabilidade nasal, em geral, é feita com base na história clínica e na rinoscopia. Entretanto, as impressões clínicas nem sempre permitem a correta identificação do comprometimento das vias 
aéreas nasais (Trindade e Trindade Junior 2000). Durante a última década, pesquisadores e clínicos têm usado métodos mais objetivos para identificar e caracterizar as alterações da função naso-respiratória inclusive para acompanhar os resultados de tratamentos cirúrgicos. A rinomanometria é o método instrumental mais utilizado para avaliar indiretamente a permeabilidade nasal e nasofaringea. Mede pressões e fluxos gerados na cavidade nasal durante a respiração e permite inferir a resistência das vias aéreas nasais. Warren (1984), com o propósito de superar a principal limitação do método, que reside no fato da resistência ser fluxo-dependente, introduziu uma modificação na rinomanometria convencional de modo a estimar não a resistência, mas a área de secção transversa mínima da cavidade nasal. A válvula nasal é usualmente a área estimada, porém se outras constrições significantes estão presentes, como o retalho faringeo, a área aferida é uma composição delas (Warren e Drake 1993). Modificações da técnica permitem, ainda, determinar de forma compartimentalizada, a área de secção transversa da cavidade nasal e da nasofaringe, separadamente. Estes foram os métodos empregados para estimar, no presente estudo, os efeitos do retalho faringeo sobre a permeabilidade da nasofaringe de fissurados de palato. 


\section{REVISÃO DE LITERATURA.}

O esfincter velofaríngeo corresponde à área limitada anteriormente pelo palato mole, lateralmente pelas paredes laterais da faringe e posteriormente pela parede posterior da faringe. Os músculos que compõem o esfincter velofaríngeo são: elevador do véu palatino, tensor do véu palatino, músculo da úvula, constritor superior da faringe, palatofaringeo, palatoglosso e salpingofaríngeo. A ação sincronizada destes músculos abre e fecha o orifício velofaríngeo como um esfincter, permitindo a comunicação ou a separação completa das cavidades oral e nasal durante a fala e outras atividades fisiológicas (Croft et al 1981 e Altmann 1997). Após o advento da videofluoroscopia e da nasoendoscopia, verificou-se que o padrão de fechamento do esfincter velofaríngeo é muito variável entre os indivíduos, tanto na população normal quanto nos pacientes com fissura palatina (Croft et al 1981). Skolnick et al (1973) descreveram quatro categorias de fechamento velofaringeo baseadas nos vários graus de movimento das estruturas do esfincter: padrão coronal, no qual predomina o movimento ântero-posterior do véu palatino, com movimento relativamente pequeno das paredes laterais da faringe e nenhum movimento da parede posterior da faringe; padrão sagital, no qual predomina a medialização das paredes laterais da faringe, com pouca movimentação do véu palatino; padrão circular, no qual há uma contribuição basicamente igual do véu e das paredes laterais da faringe, porém não há movimento da parede posterior da faringe; e, padrão circular com Anel de Passavant, no qual ocorre o movimento do padrão circular, acrescido da projeção anterior da parede posterior da faringe.

Nos indivíduos portadores de fissuras labiopalatinas, a anatomia e a fisiologia do esfincter velofaríngeo estão alteradas. Segundo Gomes e Mélega (1997), a inserção dos músculos palatinos está direcionada para frente, em 
particular do músculo elevador do véu, além de haver hipoplasia da aponeurose palatina. Nestes indivíduos, as fibras musculares não formam as cintas musculares necessárias, havendo uma alteração das forças vetoriais resultantes e, portanto, comprometimento da função do esfincter velofaríngeo.

As estruturas do mecanismo velofaringeo desempenham papel fundamental na produção da fala. Sua natureza esfinctérica permite a completa separação entre as cavidades oral e nasal durante a emissão dos sons orais da fala e outras atividades fisiológicas, de modo que, a inadequação do mecanismo velofaringeo pode afetar a fala de diferentes formas (Trindade e Trindade Junior 1996).

O termo inadequação velofaríngea é empregado na literatura para designar de maneira genérica qualquer tipo de função velofaringea anormal, conforme a classificação proposta por Trost-Cardamone (1989). A inadequação velofaringea engloba as desordens neurogênicas (incompetência velofaríngea), as deficiências de aprendizado designadas em inglês como "velopharyngeal mislearning" e as deficiências de natureza estrutural - insuficiência velofaringea - que é objeto de estudo do presente trabalho. Dalston (1991) utilizou também o termo disfunção velofaringea para definir qualquer alteração do mecanismo velofaríngeo.

Os sintomas mais comuns da insuficiência velofaringea (IVF) são a hipernasalidade, a emissão de ar nasal (audivel ou não) e os distúrbios articulatórios compensatórios (Hirschberg 1986, Bradley 1989,Yamashita 1990, D’Antonio 1992, Kummer et al 1992, Golding-Kushner 1995, Witzel 1995, Trindade e Trindade Junior 1996 e Zuiani et al 1998).

A hipernasalidade é uma das manifestações clínicas mais marcantes da IVF e pode ser descrita como uma mudança na qualidade vocal que resulta do 
acoplamento da nasofaringe com a orofaringe (Hogan e Schwartz 1977). Corresponde a um excesso de ressonância nasal acompanhando sons normalmente não nasalizados. No aspecto fisiológico, a hipernasalidade é o resultado da incapacidade do esfincter velofaringeo manter-se fechado o suficiente para evitar a ressonância nasal dos sons que normalmente são articulados oralmente (McWilliams et al 1984, Aronson 1985, Kummer et al 1992 e D’Antonio e Scherer 1995).

Assim como a hipernasalidade, a emissão de ar nasal, também é característica da IVF. Corresponde à emissão inapropriada do fluxo aéreo pelo nariz durante a produção de consoantes de pressão (Kummer et al 1992 e D’Antonio e Scherer 1995). A emissão de ar nasal é perceptível durante a produção de consoantes de pressão plosivas, fricativas e africadas. A emissão de ar nasal pode variar desde emissões não audiveis até formas mais graves de emissão audível, rotuladas de turbulência nasal (McWilliams et al 1984, Bzoch 1989 e Rocha 1990).

A ausência do fechamento velofaríngeo leva, ainda, ao aparecimento dos distúrbios articulatórios compensatórios, que podem ser considerados como estratégias para compensar a incapacidade de impor pressão na cavidade oral. Segundo Trindade e Trindade Junior (1996), em termos aerodinâmicos, a falha no desempenho articulatório das estruturas da velofaringe tem como efeito principal a geração de uma pressão intra-oral em niveis insuficientes para a produção de consoantes plosivas, fricativas e africadas, associada à emissão nasal do ar expiratório. Assim, indivíduos com IVF freqüentemente substituem os sons articulados oralmente por sons articulados em pontos aquém do local da deficiência, na tentativa, por vezes inconsciente, de aproximar o resultado acústico o mais possível daquilo que consideram como um som normal. Os distúrbios articulatórios compensatórios, secundários à IVF, mais freqüentes 
são: golpe de glote, fricativa faringea, plosiva faringea, fricativa velar, plosiva dorso-médio-palatal e fricativa nasal posterior (Trost 1981 e Golding-Kushner 1995); são adquiridos na infância, durante o processo de aquisição de linguagem e podem permanecer após a correção cirúrgica da IVF (Warren 1986 e Rocha 1990).

Como já mencionado anteriormente, no que se refere à fala, a correção cirúrgica primária da fissura palatina tem como objetivo principal estabelecer condições anatômicas para o adequado fechamento velofaríngeo (Brown et al 1983 e Dumbach 1987). Para se obter o bom funcionamento do palato e adequação do fechamento velofaringeo, a musculatura, especialmente do elevador do véu palatino, deve ser deslocada o mais posteriormente possivel (Brown et al 1983, Dumbach 1987, Butow e Jacobs 1991, Gosain et al 1996 e Rocha 1997). Entretanto, quando a cirurgia primária do palato falha em alcançar a adequação velofaríngea e, assim, eliminar os sinais clínicos da IVF, uma cirurgia secundária torna-se necessária para corrigir a fala.

Inúmeras técnicas cirúrgicas estão descritas na literatura para a correção da IVF. Rocha (1997) reuniu-as em quatro grupos: 1) aumento da parede posterior da faringe que objetiva projetar anteriormente a parede posterior da faringe, criando uma elevação contra a qual o palato toca; 2) mobilização dos músculos elevadores do palato que visa a correção da posição anômala da musculatura palatina, colocando-a em posição mais posterior, próxima ao normal (faringoplastia intra-velar); 3) retroposição do palato que visa o alongamento do palato, levando-o a uma posição mais posterior e 4) retalhos faringeos que objetivam a união entre o palato e a parede posterior da faringe.

O retalho faríngeo tem sido o procedimento mais utilizado para o tratamento cirúrgico da IVF nas últimas décadas (Hogan e Schwartz 1977 e Shprintzen et al 1979). Segundo a literatura, em 1865, Passavant realizou o 
procedimento cirúrgico considerado o precursor do retalho faríngeo, quando suturou a borda posterior do palato mole à parede posterior da faringe (Schulz et al 1973 e Sloan 2000). Mais tarde, em 1876, Schoenborn descreveu a técnica do retalho faríngeo de pedículo inferior, e em 1892, Bardenheuer introduziu a técnica de pedículo superior que foi utilizada por Sanvenero-Rosselli em 1935 (Hogan e Schwartz 1977, Shprintzen et al 1979, Hirschberg 1986 e Rocha 1997). Embora não exista consenso na literatura quanto às vantagens e desvantagens da posição da base do retalho (Trier 1985 e Sloan 2000), a técnica de pedículo inferior apresenta o inconveniente de limitar o retalho numa direção inferior a do plano palatino prejudicando o movimento necessário para o fechamento velofaríngeo completo. Além disso, a retração cicatricial que ocorre em conseqüência da cicatrização por segunda intenção da área cruenta nasal do retalho leva ao estreitamento deste, tornando-o insuficiente para o fechamento velofaringeo. Tais limitações levaram ao emprego, mais freqüente, do retalho de pedículo superior (Witt e D’Antonio 1993 e Rocha 1997).

A cirurgia de retalho de pedículo superior consiste na construção de uma ponte de tecido permanente (mucosa, submucosa e músculo) entre a parede posterior da faringe e o palato mole (Hogan e Schwartz 1977). Segundo Rocha (1997), a base do retalho faringeo deve ficar no nível do corpo da primeira vértebra cervical, que corresponde à área de transição entre a mucosa faríngea e o início do tecido adenoideano. Está demonstrado através de estudos com nasoendoscopia e videofluoroscopia que este é o local de melhor movimento das paredes laterais e posterior da faringe, o que torna o retalho mais eficiente quando está localizado nesta região. A largura do retalho é determinada conforme a intensidade dos movimentos das paredes laterais que devem ser avaliadas antes da cirurgia. A avaliação instrumental pré-operatória (nasoendoscopia e videofluoroscopia) do movimento das paredes laterais e 
posterior da faringe é de grande importância a fim de que se possa construir o retalho de acordo com as necessidades de cada caso (Argamaso et al 1980). Quando existe pouco movimento das paredes laterais da faringe ou este é inexistente, o retalho deve ter a largura de quase toda a parede posterior da faringe, deixando-se apenas 2 a $3 \mathrm{~mm}$ de distância entre o retalho e a parede lateral onde ficará a mucosa íntegra (Rocha 1997).

A técnica do retalho de pedículo segundo a descrição de Rocha (1997) é a seguinte: a cirurgia inicia-se com a divisão do palato mole na linha média, separando as duas hemiúvulas de modo a expor a faringe e suas paredes laterais. O retalho é desenhado na parede posterior da faringe em forma de "U"; é feita uma incisão na mucosa e na musculatura expondo a fáscia prévertebral, onde o retalho é então dissecado e levantado. Partindo-se do vértice da ferida criada no palato, faz-se uma incisão na mucosa nasal em direção à parede lateral da faringe até cerca de 3 a $5 \mathrm{~mm}$ do ângulo entre a parede lateral e a parede posterior da faringe. Segundo o autor, é importante que se deixe sempre uma faixa de mucosa entre esta incisão e a incisão do retalho, que constituirá o revestimento do orifício lateral, a fim de se evitar sinéquia cicatricial. Disseca-se um retalho de mucosa nasal que fica pediculado posteriormente na borda livre do palato e que servirá para a cobertura da área cruenta do retalho faringeo. Para a moldagem dos orificios laterais ao retalho, introduz-se pela narina do paciente uma sonda plástica (catéter) que servirá de referência para o tamanho dos orificios laterais. Inicia-se a sutura da mucosa nasal da parede lateral da faringe com a borda do retalho, abraçando a sonda. O autor chama atenção para o cuidado que é preciso ter para que sempre haja mucosa íntegra no perímetro dos orificios laterais, a fim de que não ocorra cicatrização total do orifício. A sonda é, então, retirada deixando os orificios laterais permeáveis e a extremidade dos retalhos da mucosa nasal do palato 
suturados na fáscia pré-vertebral próximo ao pedículo do retalho. Sutura-se o restante da ferida cirúrgica do palato, sendo que a área cruenta doadora do retalho é deixada cicatrizar por segunda intenção.

Conforme afirmam Witt e D'Antonio (1993) os orificios criados na cirurgia devem estar localizados na região de melhor movimento das paredes laterais da faringe e idealmente devem permanecer abertos durante a respiração e a produção de consoantes nasais e se manter fechados durante a produção dos sons orais da fala. Quando o retalho é muito largo, o paciente poderá desenvolver respiração oral, hiponasalidade e até distúrbios do sono que pode variar desde ronco noturno à apnéia obstrutiva do sono. Se o retalho é muito estreito, a hipernasalidade persiste como resultado da inabilidade das paredes laterais fecharem os orificios (Warren et al 1974 e Witt e D'Antonio 1993).

Preocupados com este aspecto, alguns autores propuseram condutas para controlar o tamanho dos orificios laterais. Hogan (1973), baseado em estudos aerodinâmicos da literatura, concluiu que a medida ideal do orifício velofaringeo, no repouso, para se obter a competência velofaríngea necessária para a fala, deve ser de $20 \mathrm{~mm}^{2}$ de área. O autor sugeriu o uso de catéteres colocados na região dos orificios laterais durante a cirurgia, de modo que a área resultante da soma dos dois orificios seja de $20 \mathrm{~mm}^{2}$. Shprintzen et al (1979), por sua vez, afirmaram que o sucesso da cirurgia de retalho faringeo melhora significativamente quando a largura e a inserção do retalho são "feitos sob medida" de acordo com o grau de movimento das paredes laterais da faringe e o tamanho do "gap" velofaríngeo (espaço na área velofaríngea pelo qual ocorre o escape de ar para o nariz) avaliados antes da cirurgia. Segundo Witt e D’Antonio (1993), entretanto, embora seja possivel modelar o tamanho dos orificios na cirurgia de acordo com a necessidade de cada caso, variáveis como 
cicatrização e migração pós-operatória do retalho inviabilizam o controle do tamanho dos orificios.

Apesar destas limitações, a cirurgia do retalho faríngeo, tem sido frequentemente utilizada no sentido de criar uma obstrução mecânica capaz de separar a cavidade nasal do restante do trato vocal, evitando a passagem da corrente aérea sonorizada para a cavidade nasal durante a produção dos sons orais, resultando acusticamente em diminuição da hipernasalidade e, sob o ponto de vista aerodinâmico, no aumento da pressão intra-oral durante a fala (Riski et al 1992).

Como já mencionado anteriormente, muitos autores comprovaram o elevado sucesso da cirurgia de retalho faríngeo na redução ou eliminação dos sintomas de fala conseqüentes da IVF (Smith et al 1963, Subtelny et al 1970, Owsley Junior et al 1970, Schulz et al 1973, Leanderson et al 1974, Brondsted et al 1984, Van Demark e Hardin 1985, Schmelzein et al 1992, Eufinger et al 1995, Morris et al 1995, entre outros). Bzoch, (1964), com o objetivo de investigar os efeitos da cirurgia de retalho faringeo sobre a fala, avaliou 40 pacientes antes da cirurgia e, em intervalos de 6 meses ao longo de 7 anos após a cirurgia. Os pacientes foram submetidos a estudo cefalométrico, exame oral e avaliação da fala quanto aos distúrbios articulatórios e à ressonância. Todos os pacientes apresentavam hipernasalidade antes da cirurgia e por ocasião do término do estudo, nenhum paciente apresentou hipernasalidade. Entretanto, 29 pacientes $(72,5 \%)$ passaram a apresentar hiponasalidade imediatamente após a cirurgia. Destes, 20 passaram a apresentar também respiração oral e 18 apresentaram ronco além da hiponasalidade. Um ano após a cirurgia, a hiponasalidade persistiu em 27 casos $(67,5 \%)$ e em 18 casos $(45 \%)$, um ano e meio após a cirurgia. Em nosso laboratório, também se constatou a eliminação e/ou redução da hipernasalidade secundária à IVF em pacientes fissurados. No 
entanto, verificou-se, ao mesmo tempo, por meio de nasometria, que parte deles passou a apresentar hiponasalidade, um sintoma de fala que pode refletir obstrução nasal, além de referirem dificuldades respiratórios após a faringoplastia (Zuiani 1996 e Zuiani et al 1998).

Em verdade, os sintomas respiratórios após a faringoplastia de retalho têm sido reconhecidos há muitos anos, porém somente nas últimas décadas é que começaram a ser devidamente valorizados e tratados (Warren et al 1974, Witt e D’Antonio 1993 e Sloan 2000).

Thurston et al (1980) preocupados com a possivel ocorrência de obstrução respiratória após a cirurgia de retalho faringeo realizaram um estudo com 85 pacientes, operados num período de 5 anos, os quais foram reconvocados para novas avaliações e entrevistas. O objetivo foi questioná-los sobre seus hábitos alimentares, tolerância ao exercício, padrão de sono, olfato e respiração após a cirurgia. Os pacientes foram, ainda, submetidos à nasofaringoscopia e sua permeabilidade nasal, habilidade para inspirar e expirar através de cada narina, foi testada por meio da oclusão da narina contralateral. Como resultado, os autores constataram a presença de obstrução nasal importante em $10 \%$ dos pacientes reavaliados. Apesar do fato de muitos deles terem sido acompanhados por vários anos após a cirurgia, a significância de sua obstrução nasal nunca havia sido devidamente avaliada. Segundo os autores, os pacientes, freqüentemente, não se queixam da obstrução nasal, de modo que devem ser cuidadosamente questionados e examinados no pósoperatório do retalho faríngeo, para que essas complicações possam ser diagnosticadas.

Segundo Graham et al (1973), Jackson et al (1976), Abransom et al (1997) e Wells et al (1999), maior cuidado ainda deve ser tomado quando o retalho faríngeo é realizado em pacientes portadores de síndromes associadas à 
fissura. Kravath et al (1980) relataram os casos de 3 crianças que desenvolveram apnéia obstrutiva do sono como uma complicação do retalho faríngeo, ocorrendo inclusive um óbito 4 semanas após a cirurgia. Vale ressaltar que duas destas crianças apresentavam síndrome velocardiofacial e a outra, Seqüência de Robin.

De acordo com Shprintzen (1988), muitas destas síndromes que incluem a fissura, estão associadas ao estreitamento estrutural da via aérea faríngea, como a Seqüência de Robin, ou à hipotonia da faringe, como na sindrome velocardiofacial, que podem levar a complicações tanto trans-operatórias como pós-operatórias. O autor realizou um estudo amplo em 300 pacientes com fissura de palato e IVF; destes, 204 tinham fissura isolada e 96 apresentavam fissura associada a sindromes de malformações múltiplas. Vinte e oito dos pacientes do grupo sindrômico apresentavam a sindrome velocardiofacial. Todos os pacientes foram submetidos à nasofaringoscopia, videofluoroscopia, polissonografia e avaliação de fala, antes e após a cirurgia. Como resultado, o autor verificou, no que se refere à fala, que a IVF e a ressonância anormal foram eliminadas em $97 \%$ dos pacientes, e que, em $4 \%$ dos pacientes ocorreu hiponasalidade como complicação. O autor observou também que 30 pacientes (10\%) apresentaram apnéia obstrutiva do sono ainda durante o período de internação pós-cirúrgico. Destes, 18 apresentavam síndromes de anomalias múltiplas associadas à fissura. Em 27 pacientes, a apnéia foi temporária tendo sido completamente resolvida a curto prazo. Somente em 3 pacientes persistiu a apnéia; um, não sindrômico, apresentava amígdalas hipertróficas que foram retiradas e a apnéia resolvida; um apresentava Seqüência de Robin como parte da sindrome de Stickler e, o outro, sindrome velocardiofacial, sendo que ambos não apresentavam mais a apnéia obstrutiva do sono 1 ano após a cirurgia. $O$ autor considerou alta a incidência de $10 \%$ de apnéia obstrutiva do sono numa 
amostra de 300 pacientes, e ressaltou que o simples fato de se pesquisar especificamente uma determinada complicação, como a apnéia neste estudo, já precipitaria sua identificação na amostra de pacientes.

Ainda com relação à incidência de obstrução respiratória no sono, Orr et al (1987), também submeteram 10 pacientes operados com retalho à polissonografia 1 a 2 dias antes da cirurgia, imediatamente após a cirurgia ( 2 a 3 dias após) e aproximadamente 3 meses após a cirurgia. Os autores verificaram que 9 pacientes com retalho faríngeo apresentaram apnéia obstrutiva do sono grave imediatamente após a cirurgia, e, 3 meses após, somente 2 pacientes continuaram a apresentar a apnéia. Os autores concluíram que a apnéia após o retalho é um fenômeno transitório que desaparece, na maioria dos casos, no período de 3 meses após a cirurgia e que não deveria ser considerada uma complicação da cirurgia, mas sim, um efeito transitório e esperado. Enfatizaram, ainda, a importância de se prevenir os pais dos pacientes submetidos a esta cirurgia de que o aparecimento de apnéia no sono é comum após o retalho faríngeo e que eles devem esperar a solução gradual do problema com o tempo.

Em 1988, Velasco et al também com o objetivo de pesquisar a sindrome da apnéia obstrutiva do sono e suas repercussões em seus pacientes, reavaliaram um total de 106 pacientes com retalho. Foram detectados por meio de entrevista que abordava aspectos clínicos, 16 pacientes com suspeita de apnéia os quais foram encaminhados à polissonografia. Em 9 pacientes foi confirmada a apnéia e todos foram tratados cirurgicamente (amigdalectomia e úvulo-palato-faringoplastia de Fujita modificada). Os autores recomendaram o uso da polissonografia após o retalho a fim de detectar, prevenir e planejar o tratamento da apnéia que segundo eles, frequentemente não é observada clinicamente. 
Pensler e Reich (1991), com o objetivo de avaliar o efeito da cirurgia de retalho faringeo e da esfincter-faringoplastia sobre a competência velofaringea, realizaram um estudo onde avaliaram os resultados de fala e a incidência de seqüelas pós-operatórias em 75 pacientes submetidos ao retalho faríngeo e 10 pacientes submetidos à esfincter-faringoplastia. As avaliações foram realizadas por um cirurgião plástico, um otorrinolaringologista e um fonoaudiólogo antes e após a cirurgia. Os resultados pós-cirúrgicos mostraram melhora da fala em ambas as técnicas cirúrgicas, $(75 \%$ dos pacientes submetidos ao retalho e $70 \%$ dos pacientes submetidos à esfincter-faringoplastia). Entretanto, 3 pacientes (4\%) submetidos ao retalho faríngeo apresentaram apnéia após a cirurgia. Nenhum paciente submetido à esfincter-faringoplastia apresentou apnéia. Tal resultado foi atribuído à grande diferença no número de pacientes do grupo submetido às duas cirurgias.

Caouette-Laberge et al (1992), por sua vez, reavaliaram todos os pacientes que necessitaram de revisão cirúrgica do retalho faríngeo em seu serviço, ao longo de 17 anos, e encontraram 9 pacientes que passaram a apresentar sintomas de obstrução nasal significativa após a cirurgia, tais como respiração oral, ronco constante e fala hiponasal. Estes 9 pacientes foram submetidos a um questionário, ao exame clínico, nasoendoscopia e videofluoroscopia. Embora os autores não tenham relatado apnéia obstrutiva do sono em seu estudo, todos os pacientes necessitaram de ressecção parcial ou total do retalho para correção da obstrução nasal. Em 2 casos procedeu-se à secção parcial do retalho para aumentar o tamanho dos orificios laterais e em 7, à ressecção total do retalho. Segundo os autores, quando o retalho faríngeo leva à obstrução das vias aéreas nasais, é indicada a cirurgia para ressecção completa do retalho. Enfatizaram, ainda, que existe um alto risco de obstrução 
recorrente das vias aéreas, como conseqüência da cicatrização do orifício velofaríngeo e a readerência do retalho faríngeo após a ressecção do mesmo.

Ysunza et al (1993) também relataram em seu estudo, a ocorrência de 15 casos, em que houve a necessidade de revisão cirúrgica para tratamento da apnéia obstrutiva do sono. Os autores reavaliaram 585 pacientes sendo 571 submetidos à cirurgia de retalho faringeo e 14 submetidos à esfincterfaringoplastia do tipo Jackson. Destes, 18 pacientes apresentaram sintomas clínicos de apnéia obstrutiva do sono e foram submetidos à polissonografia e nasofaringoscopia para confirmação. Em 15 pacientes (4\%), 14 com retalho faríngeo e 1 com esfincter-faringoplastia do tipo Jackson, foi confirmada a apnéia obstrutiva do sono, diagnosticada com base em achados clínicos (presença de ronco, hipersonolência, mudanças psicológicas após a cirurgia), polissonográficos e videonasofaringoscópicos. Em função do efeito potencialmente danoso da apnéia obstrutiva do sono, a prevalência de $4 \%$ observada no estudo foi considerada alta. Os autores concluíram que os sintomas da apnéia devem ser cuidadosamente investigados após a colocação do retalho e que a nasofaringoscopia deve ser realizada antes da cirurgia a fim de se detectar possiveis fatores (como amígdalas hipertróficas) que possam contribuir para o aparecimento da apnéia após a cirurgia.

Valnicek et al (1994) fizeram uma análise retrospectiva de 219 pacientes submetidos à cirurgia de retalho faringeo a fim de determinar o índice de complicações trans-operatórias deste tipo de cirurgia. As informações com relação a problemas médicos, etiologia da IVF, avaliação anestésica e incidência e gravidade das complicações trans-operatórias foram obtidas a partir dos registros médicos e visitas clínicas dos pacientes. Os autores encontraram uma incidência de $16,4 \%$ de complicações tais como, sangramento pós-operatório, obstrução das vias aéreas, arritmia, hipertensão, entre outras, nas primeiras 
24 horas após a cirurgia. No pós-operatório tardio, mais de 3 semanas após a cirurgia, verificaram que 9 pacientes $(4,1 \%)$ apresentaram apnéia obstrutiva do sono, sendo que 4 destes pacientes $(1,8 \%)$ foram submetidos à ressecção total do retalho faríngeo, 7 (3,2\%), apresentaram queixa de obstrução nasal, 9 $(4,1 \%)$, queixa de hiponasalidade significativa e $7(3,2 \%)$ foram submetidos à revisão do retalho devido à deiscência ou largura inadequada do mesmo. Os autores concluíram que, embora o retalho faríngeo seja eficiente no tratamento da IVF, está associado a um significante índice de complicações principalmente trans-operatórias e pós-operatórias imediatas.

Outros autores relataram altos índices de obstrução respiratória no sono. Sirois et al (1994) estudaram 40 pacientes que foram submetidos ao retalho faríngeo a fim de determinar a incidência de apnéia obstrutiva do sono após a cirurgia. Os pacientes foram submetidos à polissonografia 1 a 2 dias antes da cirurgia e imediatamente após a cirurgia (em média, 5 dias após). Além disso, os pacientes foram também monitorados por oximetria de pulso na sala de recuperação pós-cirúrgica. Antes da cirurgia, 9 pacientes apresentavam sintomas de obstrução das vias aéreas superiores e o exame polissonográfico pré-cirúrgico revelou que a maioria deles tinha poucos episódios de apnéia central. Após a cirurgia, os autores encontraram que 14 pacientes (35\%) apresentaram padrão de sono anormal ao exame polissonográfico. Dez destes pacientes foram avaliados alguns meses depois; 8 deles passaram a apresentar polissonografia normal e 2 ainda apresentaram apnéia. Segundo os autores, a polissonografia não teve valor prognóstico para as anormalidades pósoperatórias encontradas. Relataram, entretanto, que a porcentagem de tempo em que o paciente permanecia com uma saturação de oxigênio arterial menor que $90 \%$ era um bom indicador do aparecimento de distúrbios respiratórios 
clinicamente significantes, ressaltando que a polissonografia deveria ser realizada apenas nos casos de alto risco.

Lesavoy et al (1996) também verificaram uma alta prevalência de obstrução das vias aéreas superiores no pós-operatório imediato do retalho faríngeo. Os autores avaliaram 29 pacientes com IVF que foram submetidos ao retalho. O grau de obstrução das vias aéreas superiores foi classificado de acordo com os sinais e sintomas relatados pelos pacientes ou observados pelos profissionais, como: $(0)=$ nenhuma; $(1)=$ ronco ou respiração oral e freqüentes despertares; (2)=ronco, respiração oral, freqüentes despertares e hipersonolência durante o dia. Dos 29 pacientes estudados, 11 (38\%) apresentaram evidências de apnéia obstrutiva do sono e obstrução das vias aéreas superiores após o retalho. Após 2 a 5 meses, somente em 2 pacientes persistiram os sintomas de apnéia os quais desapareceram 2 anos após a cirurgia.

Como já mencionado, em nosso laboratório, Zuiani (1996) e Zuiani et al (1998) realizaram um estudo com o objetivo de avaliar os efeitos da cirurgia de retalho faringeo sobre a ressonância da fala de pacientes com IVF. Foram avaliados 20 pacientes, em média, 2 dias antes e 2 a 8 meses após a cirurgia. Os pacientes foram submetidos a um questionário para levantamento de sintomas clínicos, além da avaliação perceptiva e nasométrica da fala. Verificou-se que, após a cirurgia, 35\% dos pacientes (7 em 20) desenvolveram hiponasalidade. Além disso, 7 pacientes passaram a relatar dificuldade discreta em respirar pelo nariz, 5 passaram a apresentar ronco no sono e 2 pacientes apresentaram queixas de obstrução nasal grave após o retalho.

Com a intenção de avaliar os resultados da cirurgia de retalho faríngeo, especificamente para investigar a incidência de apnéia do sono e a necessidade de revisão cirúrgica, Wells et al (1999) realizaram um estudo retrospectivo no 
qual foram analisados os registros médicos de 111 pacientes submetidos à cirurgia de retalho faringeo. Oitenta e cinco pacientes, apresentavam fissura de palato e 12 deles apresentava síndrome associada à fissura. Os autores encontraram uma incidência de $10 \%$ de complicações pós-operatórias imediatas sendo, $7 \%$ de obstrução das vias aéreas superiores, $1,8 \%$ de deiscência do retalho e $0,9 \%$ de hemorragia peri-operatória e $21,6 \%$ de complicações tardias ou resultados insatisfatórios: 12 pacientes apresentaram obstrução respiratória noturna, 3 apresentaram obstrução nasal, 6 apresentaram hiponasalidade sendo que 4 destes apresentaram também obstrução respiratória noturna e 3 hipernasalidade. Os autores observaram também uma maior incidência de obstrução respiratória nos pacientes sindrômicos. Dos 12 pacientes que apresentaram obstrução respiratória no sono, 9 foram submetidos ao estudo do sono, no mínimo 6 meses após a cirurgia, e, em 8 deles o resultado do exame foi normal. Somente em 1 paciente foi identificada apnéia obstrutiva e central. Os autores concluíram que obstrução respiratória noturna não é o mesmo que apnéia sendo este achado comum no período pós-operatório imediato e se resolve na maioria dos casos.

De Serres et al (1999) estudaram os resultados de fala e as complicações respiratórias do retalho faringeo e da esfincter-faringoplastia. Analisaram 34 pacientes com IVF, 16 dos quais foram submetidos à esfincter-faringoplastia e 18 submetidos à faringoplastia de retalho faringeo. Os autores verificaram uma tendência de melhores resultados de fala com a esfincter-faringoplastia embora não tenham observado diferenças estatisticamente significantes. Os autores verificaram também que, embora tenham observado hiponasalidade $\mathrm{e}$ dificuldades respiratórias durante o sono no pós-operatório das duas técnicas cirúrgicas, somente nos casos de retalho faríngeo foi confirmada a apnéia obstrutiva do sono pelo estudo do sono. 
Peña et al (2000) também realizaram um estudo retrospectivo com o objetivo de determinar a incidência de complicações das vias aéreas após a cirurgia de retalho faringeo. Foram revisados os registros de 87 pacientes portadores de IVF que foram submetidos à cirurgia de retalho faríngeo. A amostra de pacientes compreendeu portadores de fissura de lábio e palato, portadores de sindromes com anomalias craniofaciais e indivíduos com outras anomalias como déficit neuromuscular, doença cardíaca, microcefalia. Os autores verificaram uma incidência de $16 \%$ de complicações das vias aéreas. Cinco destes tiveram mais que uma complicação sendo que uma criança foi a óbito. Todas as complicações respiratórias ocorreram nos primeiros 4 dias após a cirurgia. Os autores concluíram que o comprometimento das vias aéreas após a cirurgia de retalho, embora incomum, pode ser potencialmente fatal.

Jorge (2002), em estudo realizado no Hospital de Reabilitação de Anomalias Craniofaciais, avaliou os efeitos do retalho faringeo sobre os niveis de saturação de oxigênio arterial em 18 pacientes fissurados por meio de oximetria, realizada na noite anterior à cirurgia e, aproximadamente 50-60 horas e 30-90 dias após a cirurgia. O autor verificou que $78 \%$ dos pacientes apresentaram dessaturação de oxigênio no pós-operatório imediato e 50\% dos pacientes ainda apresentavam dessaturação no pós-operatório mais tardio e sugeriu que, nestes casos, em que ocorre a persistência da obstrução respiratória, atenção e cuidados especiais devem ser dispensados incluindo a realização de avaliação polissonográfica periódica.

Finalmente, Liao et al (2002) realizaram um estudo com o objetivo de investigar, a longo prazo, a incidência e gravidade de apnéia obstrutiva do sono em pacientes submetidos à cirurgia de retalho faríngeo, e ainda, determinar se a idade e a largura do retalho tem efeito sobre o aparecimento da apnéia do sono. Foram estudados 10 adultos e 28 crianças com fissura de palato e IVF 
que foram submetidos à avaliação perceptiva da fala, nasofaringoscopia e videofluoroscopia pré-cirúrgicas. Um exame polissonográfico foi realizado cerca de 9 a 11 meses após a cirurgia em todos os pacientes. Os autores verificaram uma incidência de 92\% de apnéia obstrutiva do sono cerca de 6 meses após a cirurgia nos dois grupos etários estudados. Os autores explicaram que a maior incidência de apnéia encontrada em seu estudo comparativamente com a literatura, deve-se aos diferentes critérios utilizados para determinar a presença da apnéia em adultos e crianças. Verificaram, ainda, que 36 pacientes passaram a apresentar ronco após a cirurgia. Os autores não encontraram nenhuma relação entre a largura do retalho e a incidência ou a gravidade da apnéia. Também verificaram que a variável idade não tem efeito sobre a apnéia; entretanto, constataram que a idade parece influenciar a gravidade da apnéia uma vez que o grupo de crianças apresentou níveis de apnéia moderada a severa e o grupo de adultos niveis levemente anormais.

Os estudos relatados demonstram, portanto, que o retalho faríngeo está diretamente associado a um potencial significante de comprometimento de vias aéreas nasais. Como a fissura palatina freqüentemente determina deformidades nasais que diminuem as dimensões da cavidade nasal e aumentam a resistência ao fluxo aéreo respiratório (Warren at al 1974 e Warren et al 1992) parece razoável supor que a colocação de um retalho na região da nasofaringe em pacientes já portadores de obstrução nasal aumentaria a prevalência das complicações respiratórias. Estudos utilizando a rinomanometria convencional para avaliar a resistência nasal forneceram evidências de "sobrecorreção" da IVF com a cirurgia de retalho faringeo.

Warren et al (1974) constataram que o retalho faríngeo levou 20 pacientes operados a uma resistência nasal aumentada, comparativamente à 
resistência nasal de 29 indivíduos normais, de magnitude suficiente para produzir uma respiração oral em pacientes jovens, mas não nos adultos. Segundo os autores, no caso do paciente adulto, com as tonsilas palatinas e faríngea já atrofiadas, o retalho ocuparia um espaço fisiologicamente insignificante quando comparado com o espaço nasofaríngeo total.

Smith et al (1985) também utilizaram a rinomanometria para avaliar os resultados da cirurgia de retalho faríngeo. Em seu estudo, os autores consideraram a cirurgia bem sucedida quando o paciente apresentava após a cirurgia: 1) ótimo equilíbrio da ressonância oro-nasal com pouco ou nenhum fluxo nasal durante a produção de sons orais da fala, fluxo nasal adequado em sons nasais e leve resistência nasal ou 2) equilíbrio de ressonância oro-nasal aceitável com pequeno "gap" velofaríngeo durante a fala, fluxo nasal adequado durante a produção dos sons nasais e, respiração nasal adequada ou por leve obstrução nasofaríngea com fechamento velofaríngeo adequado na produção de sons orais com redução de fluxo nasal na produção de sons nasais e aumento da resistência nasal. A cirurgia foi considerada sem sucesso quando: 1) não se obtinha fechamento velofaríngeo após o retalho, ou, 2) quando ocorria obstrução nasofaríngea significativa, com redução ou eliminação do fluxo nasal durante a produção dos sons nasais e dificuldade respiratória nasal associada a aumento da resistência nasal. Como resultado, verificaram que $52 \%$ das cirurgias foram consideradas bem sucedidas, sendo $26 \%$ com resultado ótimo, 7\% com resultado adequado e um "gap" velofaríngeo mínimo e 19\% com resultado aceitável mas leve obstrução nasofaríngea. Entre os $48 \%$ de casos considerados sem sucesso, $13 \%$ foram associados com uma função velofaríngea inadequada e $35 \%$ foram caracterizados por significativa obstrução nasofaríngea ou sobrecorreção da insuficiência velofaringea. Os autores concluíram que as medidas de pressão e fluxo podem ser usadas para fornecer 
informações fisiológicas objetivas que permitem aferir a competência velofaringea na fala após a cirurgia, assim como seu efeito sobre a permeabilidade da via aérea nasofaríngea.

Finalmente, Witsell et al (1994) realizaram um estudo preliminar em 7 pacientes, no qual demonstraram que o retalho faríngeo tem um efeito variável sobre a via aérea nasal dos pacientes fissurados. Os autores encontraram, modificações para mais e para menos, da área de secção transversa mínima nasal, que incorpora a medida da nasofaringe, induzidas pelo retalho, predominando a redução. Atribuíram esse efeito variável à presença de obstrução nasal prévia em parte dos pacientes analisados. Confirmou-se, em 5 pacientes, que o retalho diminuiu ainda mais a via aérea nasal dos pacientes, o que explicaria o aparecimento das já conhecidas complicações como ronco, obstrução nasal crônica e apnéia obstrutiva do sono.

Do exposto acima, pode-se verificar que as repercussões respiratórias do retalho faringeo no paciente fissurado são as mais variadas, podendo ser observados desde sintomas leves, como respiração oral, até a apnéia obstrutiva do sono. A maioria dos estudos na literatura salvo os estudos de Warren et al (1974), Smith et al (1985) e Witsell et al (1994), utilizaram o levantamento de sintomas clínicos de obstrução respiratória para avaliar o efeito da cirurgia de retalho faríngeo sobre a respiração do paciente fissurado de palato. Apesar da reconhecida importância do julgamento clínico, é notório que existe um potencial significante de variações no que se define como sucesso e falha cirúrgica. Para se complementar as informações aferidas em avaliação subjetiva, métodos objetivos e instrumentais são necessários (Trindade e Trindade Junior 1996). Tais métodos devem refletir as mudanças anatômicas e funcionais promovidas pela cirurgia e fornecer informações objetivas sobre o 
efeito do retalho sobre o grau de permeabilidade nasal, o que foi o propósito do presente estudo. 


\section{OBJETIVOS.}

Considerando que a cirurgia de retalho faríngeo é um procedimento adequado para a eliminação ou melhora da hipernasalidade e de outros sintomas de fala associados à insuficiência velofaríngea, e, considerando que a cirurgia pode levar, também, à obstrução nasal, mais precisamente ao nivel da nasofaringe, o presente estudo teve por objetivo investigar:

1) o aparecimento de queixas respiratórias após a cirurgia;

2) a ocorrência de redução significativa das dimensões da nasofaringe com a construção do retalho faringeo, aferida por meio de rinomanometria;

3) a relação entre as queixas respiratórias e as dimensões nasofaringeas pós-cirúrgicas, e,

4) a persistência de eventuais alterações induzidas pela cirurgia ao longo do tempo. 


\section{MATERIAL E MÉTODO.}

\subsection{População estudada.}

O estudo foi realizado no Laboratório de Fisiologia do Hospital de Reabilitação de Anomalias Craniofaciais, Universidade de São Paulo (HRACUSP), em indivíduos com fissura de palato associada ou não à fissura de lábio, já submetidos à cirurgia corretora primária. Todos os pacientes incluídos no estudo eram portadores de IVF e foram selecionados entre os pacientes internados ou aguardando internação para a cirurgia de retalho faríngeo. $O$ diagnóstico clínico da IVF era realizado previamente no setor de Fonoaudiologia e complementado por avaliação aerodinâmica da área velofaríngea (anexo 1, tabela1A). Não foram incluídos no estudo pacientes com sindromes e/ou problemas neurológicos óbvios, com sintomas respiratórios ou alérgicos que resultassem em congestão nasal ao exame, com incompetência labial e com fistulas de palato residuais.

Com base em observações feitas durante ou após a execução das avaliações, foram excluídos do estudo 8 pacientes dos 66 inicialmente selecionados, pelas seguintes razões: 2 pacientes foram submetidos à cirurgia nasal (rinosseptoplastia) após a faringoplastia, no intervalo entre a cirurgia e a segunda avaliação pós-operatória; 2 pacientes apresentaram desempenho tecnicamente insatisfatório durante a avaliação rinomanométrica; 3 pacientes não realizaram as duas avaliações pós-cirúrgicas; 1 paciente foi submetido à revisão da cirurgia para retirada do retalho faringeo um mês após a cirurgia, pois desenvolveu obstrução respiratória grave durante o sono, após a faringoplastia.

Assim sendo, fizeram parte do estudo 58 pacientes, os quais foram divididos em 2 grupos com base na presença ou ausência de queixas 
respiratórias relatadas por ocasião do término do estudo, ou seja, na $2^{\mathrm{a}}$ avaliação pós-cirúrgica realizada (POS2):

- Grupo com queixas (CQ): composto por 21 pacientes que relataram as seguintes queixas respiratórias em POS2: respiração oral diurna e/ou durante o sono, ronco e dificuldade respiratória durante o sono. Foram considerados apenas relatos de piora de sintomas pré-existentes ou o aparecimento de queixas respiratórias não relatadas antes da cirurgia.

- Grupo sem queixas (SQ): composto por 37 pacientes que não relataram queixas respiratórias em POS2.

A idade dos pacientes do grupo CQ variou entre 8 e 57 anos (média $=17$ anos) por ocasião da avaliação pré-operatória e da cirurgia. Treze pacientes eram do sexo masculino e 8 pacientes do sexo feminino. Dez pacientes apresentavam fissura de palato isolada e 11 pacientes apresentavam fissura de palato associada à fissura de lábio, previamente operadas (tabela 1).

A idade dos pacientes do grupo SQ variou entre 9 e 46 anos (média $=21$ anos) por ocasião da avaliação pré-operatória e da cirurgia. Vinte e dois pacientes eram do sexo masculino e 15 pacientes do sexo feminino. Sete pacientes apresentavam fissura de palato isolada, 20 pacientes apresentavam fissura de palato associada à fissura de lábio unilateral e 10 pacientes apresentavam fissura de palato associada à fissura de lábio bilateral, previamente operadas (tabela 2). 
Tabela 1 - Dados gerais sobre os pacientes do grupo com queixas respiratórias (CQ) e etapas da avaliação relativamente à cirurgia de retalho faríngeo.

\begin{tabular}{|c|c|c|c|c|c|c|}
\hline \multirow[b]{2}{*}{ Paciente } & \multirow[b]{2}{*}{$\begin{array}{l}\text { Idade } \\
\text { anos }\end{array}$} & \multirow[b]{2}{*}{ Sexo } & \multirow[b]{2}{*}{ Fissura } & \multicolumn{3}{|c|}{ Avaliações } \\
\hline & & & & $\begin{array}{l}\text { PRE } \\
\text { dias }\end{array}$ & $\begin{array}{l}\text { POS1 } \\
\text { meses }\end{array}$ & $\begin{array}{l}\text { POS2 } \\
\text { meses }\end{array}$ \\
\hline 1 & 13 & Fem & FP & 2 & 3 & 13 \\
\hline 2 & 13 & Masc & FLPU & 1 & - & 13 \\
\hline 3 & 57 & Fem & FLPU & 6 & 3 & 19 \\
\hline 4 & 28 & Masc & FLPU & 1 & 5 & 10 \\
\hline 5 & 21 & Fem & FLPU & 1 & 6 & 13 \\
\hline 6 & 21 & Masc & $\mathrm{FP}$ & 5 & 6 & 20 \\
\hline 7 & 11 & Masc & $\mathrm{FP}$ & 2 & 10 & 16 \\
\hline 8 & 9 & Masc & FLPU & 1 & 3 & 21 \\
\hline 9 & 15 & Masc & $\mathrm{FP}$ & 1 & 5 & 12 \\
\hline 10 & 8 & Masc & $\mathrm{FP}$ & 4 & 3 & 12 \\
\hline 11 & 12 & Masc & FLPU & 15 & 5 & 23 \\
\hline 12 & 9 & Masc & FLPU & 1 & 6 & 12 \\
\hline 13 & 10 & Fem & $\mathrm{FP}$ & 2 & 5 & 12 \\
\hline 14 & 22 & Masc & FLPU & 1 & 3 & 12 \\
\hline 15 & 27 & Masc & FLPU & 1 & - & 15 \\
\hline 16 & 12 & Fem & $\mathrm{FP}$ & 1 & 5 & 14 \\
\hline 17 & 9 & Fem & FP & 1 & 6 & 12 \\
\hline 18 & 10 & Masc & FLPU & 5 & - & 12 \\
\hline 19 & 17 & Masc & FLPU & 1 & 8 & 12 \\
\hline 20 & 13 & Fem & FP & 2 & 4 & 12 \\
\hline 21 & 30 & Fem & FP & 1 & 4 & 17 \\
\hline$\overline{\mathrm{X}}$ & 17 & & & 3 & 5 & 14 \\
\hline$\pm \mathrm{DP}$ & 11 & & & 3 & 2 & 4 \\
\hline
\end{tabular}

$\mathrm{FP}=$ Fissura de palato

PRE = Pré-cirúrgica

FLPU = Fissura de lábio e palato unilateral POS1 $=1^{\text {a }}$ Avaliação Pós-cirúrgica Fem = Sexo feminino POS2 $=2^{\mathrm{a}}$ Avaliação Pós-cirúrgica 
Tabela 2 - Dados gerais sobre os pacientes do grupo sem queixas respiratórias (SQ) e etapas da avaliação relativamente à cirurgia de retalho faríngeo.

\begin{tabular}{|c|c|c|c|c|c|c|}
\hline \multirow[b]{2}{*}{ Paciente } & \multirow{2}{*}{$\begin{array}{l}\text { Idade } \\
\text { anos }\end{array}$} & \multirow{2}{*}{ Sexo } & \multirow[b]{2}{*}{ Fissura } & \multicolumn{3}{|c|}{ Avaliações } \\
\hline & & & & $\begin{array}{l}\text { PRE } \\
\text { dias }\end{array}$ & $\begin{array}{l}\text { POS1 } \\
\text { meses }\end{array}$ & $\begin{array}{l}\text { POS2 } \\
\text { meses }\end{array}$ \\
\hline 1 & 11 & Fem & FLPU & 1 & 9 & 11 \\
\hline 2 & 12 & Masc & FLPU & 1 & 5 & 12 \\
\hline 3 & 29 & Masc & FLPB & 1 & 3 & 14 \\
\hline 4 & 46 & Masc & $\mathrm{FP}$ & 1 & 3 & 20 \\
\hline 5 & 9 & Fem & FLPU & 5 & - & 11 \\
\hline 6 & 16 & Fem & $\mathrm{FP}$ & 4 & 3 & 12 \\
\hline 7 & 30 & Fem & FP & 2 & - & 12 \\
\hline 8 & 27 & Masc & FLPB & 2 & 5 & 11 \\
\hline 9 & 18 & Masc & FLPB & 4 & - & 12 \\
\hline 10 & 17 & Masc & FLPU & 5 & 6 & 12 \\
\hline 11 & 18 & Fem & FLPU & 2 & 6 & 12 \\
\hline 12 & 10 & Masc & FLPU & 1 & 9 & 12 \\
\hline 13 & 18 & Fem & FLPU & 2 & 6 & 12 \\
\hline 14 & 16 & Fem & FLPB & 1 & 3 & 12 \\
\hline 15 & 24 & Masc & FLPU & 1 & 5 & 14 \\
\hline 16 & 10 & Masc & FLPU & 3 & 3 & 12 \\
\hline 17 & 23 & Masc & FLPU & 1 & 2 & 13 \\
\hline 18 & 19 & Fem & FLPU & 5 & 3 & 17 \\
\hline 19 & 34 & Masc & FLPU & 1 & 4 & 12 \\
\hline 20 & 20 & Fem & FLPU & 1 & 4 & 12 \\
\hline 21 & 20 & Masc & FLPU & 4 & 6 & 14 \\
\hline 22 & 25 & Masc & FLPB & 1 & 6 & 14 \\
\hline 23 & 26 & Masc & $\mathrm{FP}$ & 1 & 3 & 12 \\
\hline 24 & 20 & Masc & FLPU & 1 & 3 & 13 \\
\hline 25 & 16 & Masc & FLPU & 1 & 5 & 24 \\
\hline 26 & 34 & Fem & FLPU & 5 & 3 & 13 \\
\hline 27 & 13 & Masc & FLPB & 3 & 5 & 12 \\
\hline 28 & 29 & Masc & FLPB & 3 & 9 & 14 \\
\hline 29 & 15 & Fem & $\mathrm{FP}$ & 1 & 6 & 16 \\
\hline 30 & 25 & Fem & $\mathrm{FP}$ & 0 & 3 & 13 \\
\hline 31 & 24 & Fem & FLPU & 1 & 3 & 22 \\
\hline 32 & 29 & Fem & $\mathrm{FP}$ & 4 & 3 & 13 \\
\hline 33 & 25 & Fem & FLPU & 1 & 8 & 19 \\
\hline 34 & 18 & Masc & FLPB & 7 & 6 & 31 \\
\hline 35 & 14 & Masc & FLPU & 1 & 4 & 15 \\
\hline 36 & 19 & Masc & FLPB & 1 & - & 12 \\
\hline 37 & 14 & Masc & FLPB & 1 & 6 & 15 \\
\hline $\bar{X}$ & 21 & & & 2 & 5 & 14 \\
\hline$\pm \mathrm{DP}$ & 8 & & & 2 & 2 & 4 \\
\hline \multicolumn{4}{|c|}{$\begin{array}{l}\text { FP = Fissura de palato } \\
\text { FLPU = Fissura de lábio e palato unilateral } \\
\text { FLPB = Fissura de lábio e palato bilateral } \\
\text { Fem = Sexo feminino } \\
\text { Masc = Sexo masculino }\end{array}$} & \multicolumn{3}{|c|}{$\begin{array}{l}\mathrm{PRE}=\text { Pré-cirúrgica } \\
\mathrm{POS} 1=1^{\mathrm{a}} \text { Avaliação Pós-cirúrgica } \\
\mathrm{POS} 2=2^{\mathrm{a}} \text { Avaliação Pós-cirúrgica }\end{array}$} \\
\hline
\end{tabular}




\subsection{Procedimento.}

O presente estudo foi, previamente, submetido à análise do Comitê de Ética em Pesquisa do Hospital de Reabilitação de Anomalias Craniofaciais, recebendo parecer favorável à sua realização (anexo 2).

Todos os pacientes foram submetidos à cirurgia de retalho faringeo de pedículo superior. Os pacientes foram submetidos a um questionário específico para levantamento da história clínica (anexo 3 - quadro 1A) e à avaliação rinomanométrica para a medida das áreas de secção transversa mínima interna da cavidade nasal e da nasofaringe na respiração de repouso, que para fins de simplificação serão denominadas, a partir deste ponto, como “área nasal" e "área nasofaringea", respectivamente.

As avaliações foram realizadas num intervalo de 0 a 15 dias (2 dias, em média) antes da cirurgia e em dois momentos após a cirurgia: 1) primeiro pósoperatório $(\mathrm{POS} 1)=2$ a 10 meses (5 meses, em média) após a cirurgia e 2) segundo pós-operatório $(\mathrm{POS} 2)=10$ a 31 meses $(14$ meses, em média) após a cirurgia (tabelas 1 e 2).

\subsubsection{Levantamento da história clínica.}

Todos os pacientes foram submetidos a um questionário para levantamento de sinais e sintomas respiratórios antes e nas duas avaliações após a cirurgia de retalho faringeo, adaptado de Caouette-Laberge et al (1992) e mostrado no anexo 3 - quadro 1A. Para fins de análise, foram especialmente consideradas informações referentes à: 1) respiração oral, 2) ronco durante o sono e 3) dificuldade respiratória durante o sono.

As queixas respiratórias apresentadas antes da cirurgia e relatadas novamente após a cirurgia não foram consideradas para análise. 


\subsubsection{Avaliação aerodinâmica da área nasal e nasofaríngea.}

\section{Equipamento}

A determinação das áreas nasal e nasofaringea foi feita por meio da rinomanometria modificada (técnica fluxo-pressão), utilizando um sistema computadorizado PERCI-SARS (Microtronics Corp, versão 3.0). A técnica baseia-se no fato de que a área de secção transversa mínima de uma constrição (ou orifício) pode ser estimada pela medida simultânea da pressão diferencial através da constrição e do fluxo aéreo que a atravessa.

\section{Medida da área nasal por meio de rinomanometria posterior}

A medida da área nasal é realizada durante a respiração de repouso. A pressão diferencial através da cavidade nasal é medida por meio de dois transdutores de pressão conectados a dois catéteres, o primeiro posicionado no interior da cavidade oral e o segundo conectado a uma máscara posicionada sobre o nariz. O fluxo nasal é medido com um pneumotacógrafo aquecido conectado à máscara nasal e ligado a um transdutor de pressão. O indivíduo é solicitado a respirar pelo nariz o mais naturalmente possivel. Os sinais de pressão e fluxo resultantes são transmitidos ao sistema PERCI computadorizado para registro e análise. As medidas são feitas no pico dos fluxos inspiratório e expiratório em duas a quatro respirações sucessivas. A área nasal considerada para análise corresponde à média dessas múltiplas medidas. Para fins de análise, foram considerados neste estudo apenas os valores observados na expiração.

A área nasal é calculada pela equação: $A=V / \mathrm{o}_{\mathrm{o}}(2 \Delta \mathrm{P} / \mathrm{d})^{1 / 2}$, onde $\mathrm{A}=$ área do orificio em $\mathrm{cm}^{2} ; \mathrm{V}^{0}=$ fluxo nasal $\mathrm{em} \mathrm{cm}^{3} / \mathrm{s} ; \mathrm{k}=0,65 ; \Delta \mathrm{P}=$ pressão oral-nasal 
em dinas $/ \mathrm{cm}^{2} ; \mathrm{d}=$ densidade do ar $\left(0.001 \mathrm{~g} / \mathrm{cm}^{3}\right)$. O valor encontrado é uma estimativa da secção transversa mínima nasal interna bilateral (direita + esquerda) na respiração de repouso e será designada, a partir deste ponto, como ANp, ou seja, área nasal total medida por rinomanometria posterior. Se existe obstrução significativa ao nível da nasofaringe, como a induzida por retalho faríngeo, a área medida na rinomanometria posterior é uma composição das duas áreas de constricção, ou seja, pode ser menor do que a área real de secção transversa mínima da cavidade nasal. A figura 1 mostra uma representação esquemática da instrumentação utilizada para estimar a área nasal.

Medida da área nasal por meio de rinomanometria anterior

Para fins de comparação, a área nasal foi também estimada por rinomanometria anterior, através da qual é medida a área nasal unilateral (direita e esquerda) isoladamente e a área total (bilateral) é então calculada pela soma algébrica das áreas unilaterais. Diferentemente do que ocorre na medida feita pela rinomanometria posterior, neste caso a medida não incorpora possiveis constricções ao nivel da nasofaringe, mas sim apenas da região anterior da cavidade nasal. O exame é realizado durante a respiração de repouso como na rinomanometria posterior. Neste caso, o fluxo aéreo nasal é medido posicionando um tubo plástico na narina em que se deseja medir a área nasal. A outra extremidade do tubo é conectada a um pneumotacógrafo aquecido, que é ligado a um transdutor de pressão. A pressão nasal é medida posicionando um catéter, no interior da outra narina, na região do vestíbulo, mantido em posição por uma rolha de cortiça que bloqueia a narina, criando uma coluna de ar estática. Na outra extremidade, o catéter é conectado a um transdutor de pressão. 


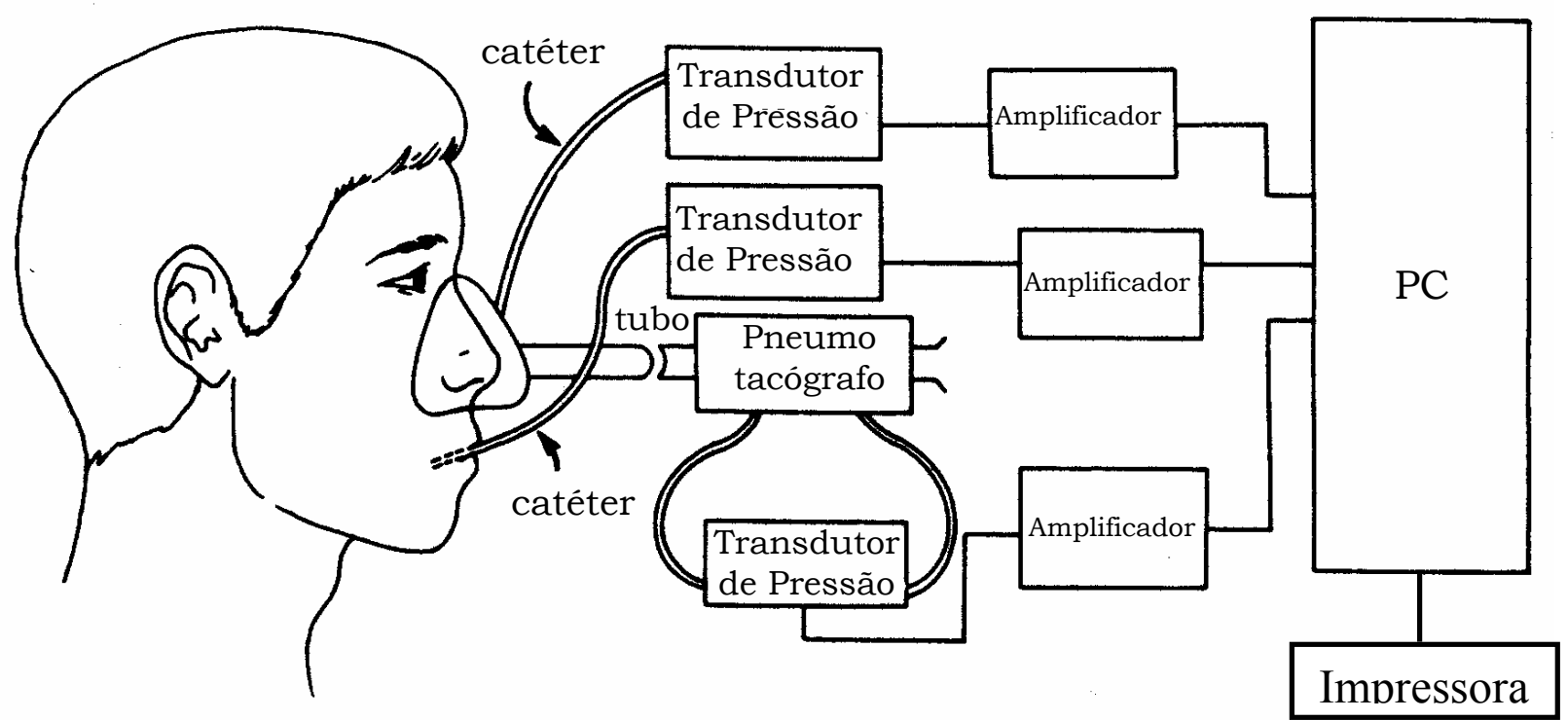

Figura 1 - Rinomanometria posterior: instrumentação para estimar a área de secção transversa mínima nasal (ANp) (Sistema PERCI-SARS, Microtronics Corp., Carrboro, NC, USA) 
Posteriormente, a posição do tubo e do catéter é invertida, para a medida da área nasal da outra narina. A área nasal unilateral é calculada utilizando o mesmo procedimento e a mesma fórmula descrita para a rinomanometria posterior, sendo a área nasal total calculada pela soma algébrica das medidas unilaterais, a qual será designada como ANa, ou seja, área nasal total medida por rinomanometria anterior, a partir deste ponto. A figura 2 mostra uma representação esquemática da instrumentação utilizada para estimar a área nasal unilateral.

Medida da área nasofaringea por meio de rinomanometria anterior modificada

O exame é realizado durante a respiração de repouso como nas avaliações anteriores. Neste caso, a pressão diferencial através da região nasofaringea é medida posicionando-se um catéter no interior da boca e outro na narina de menor fluxo. O catéter nasal é mantido em posição por uma rolha de cortiça que bloqueia a narina, criando uma coluna de ar estática, permitindo, assim, a medida da pressão na nasofaringe. O fluxo aéreo nasal é medido posicionando um tubo plástico na narina de maior fluxo. O tubo é conectado ao pneumotacógrafo aquecido ligado a um terceiro transdutor cujos sinais são enviados ao PERCI-SARS. A área nasofaringea é calculada usando o mesmo procedimento e a mesma fórmula utilizada para o cálculo da área nasal. A figura 3 mostra uma representação esquemática da instrumentação utilizada para estimar a área nasofaríngea.

A calibração do sistema PERCI-SARS era feita antes de cada exame contra um sinal de pressão de $6 \mathrm{cmH}_{2} \mathrm{O}$ fornecido por um manômetro de água e de um fluxo de $250 \mathrm{ml} / \mathrm{s}$ fornecido por um rotâmetro. 


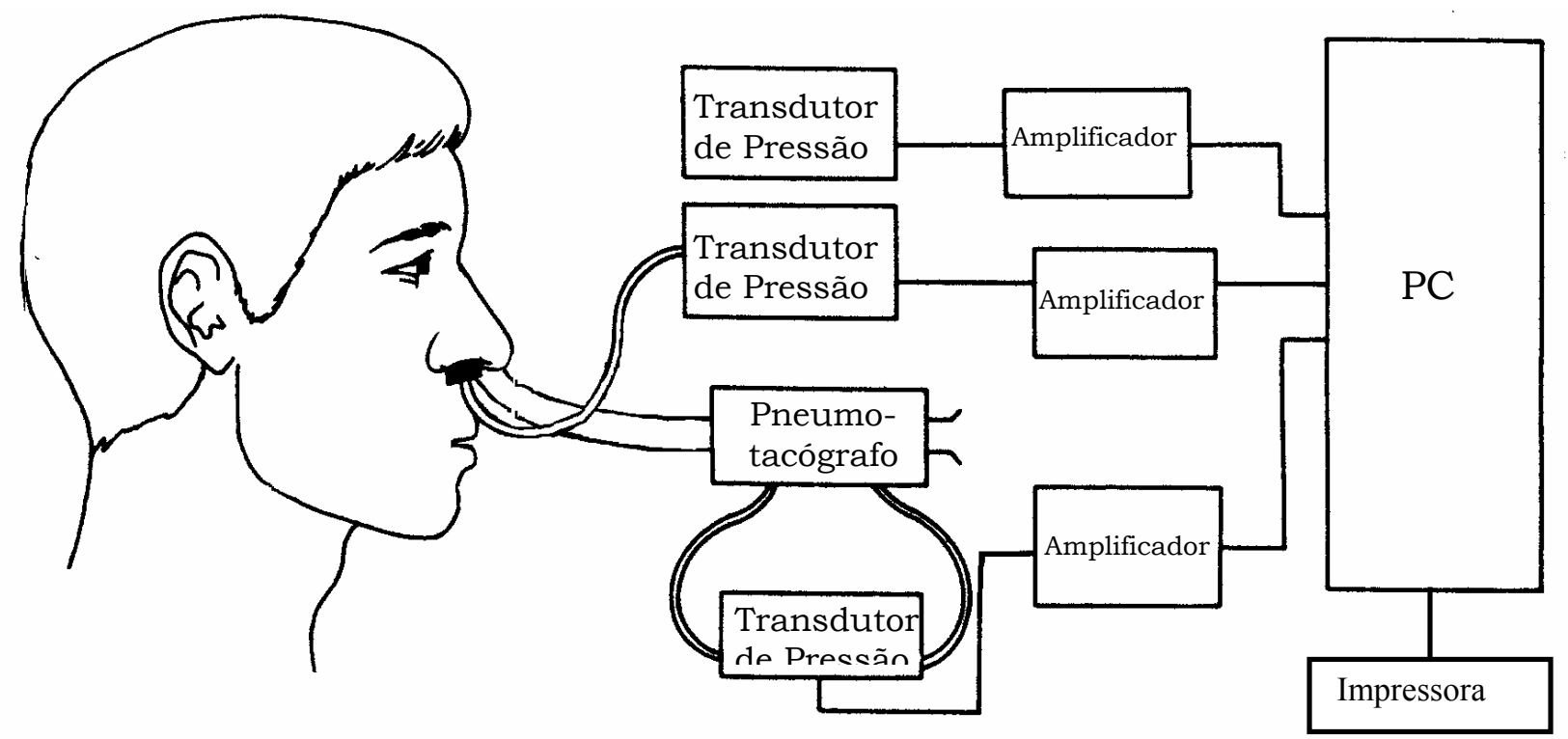

Figura 2 - Rinomanometria anterior: instrumentação para estimar a área de secção transversa mínima nasal anterior (ANa) (Sistema PERCI-SARS, Microtronics Corp., Carrboro, NC, USA) 


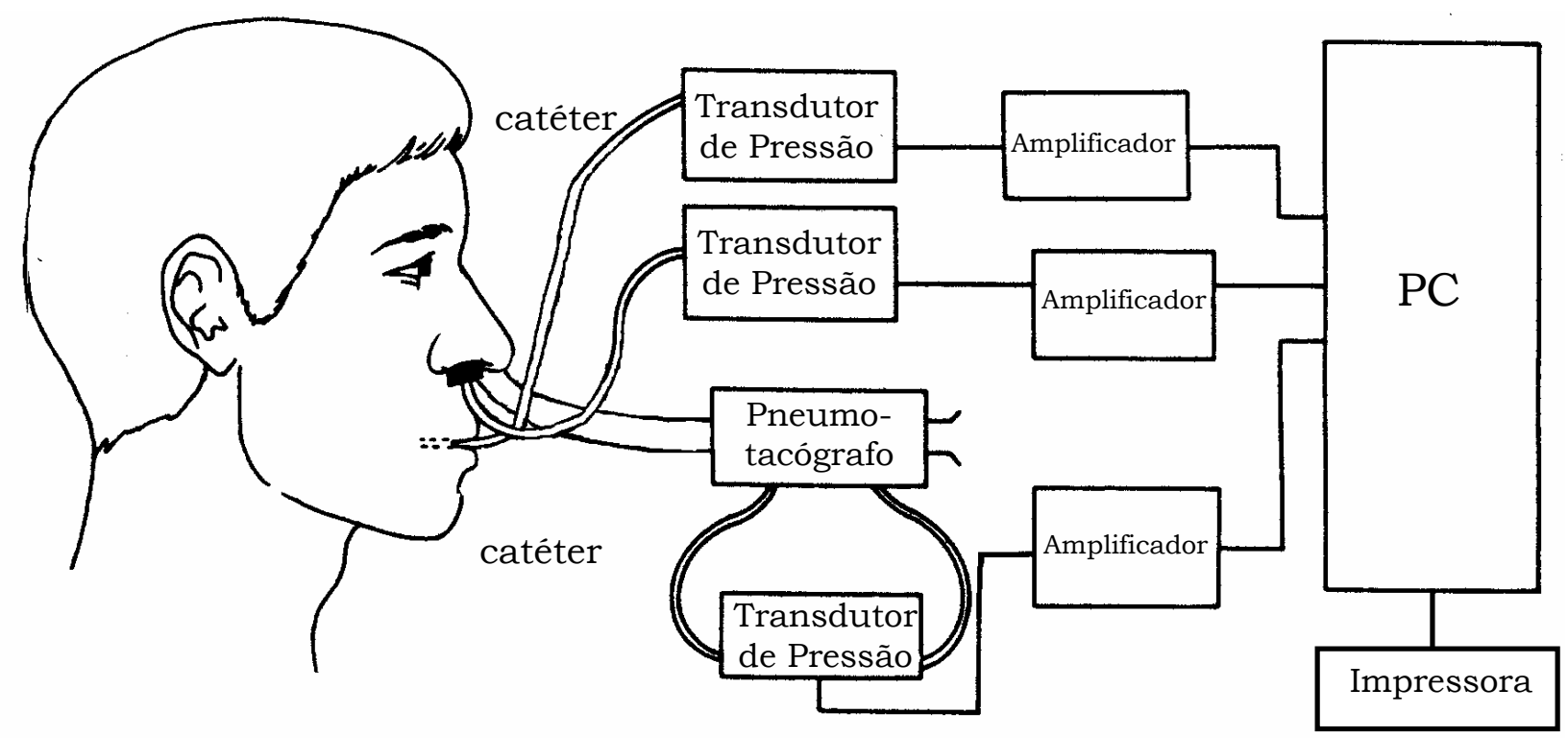

Figura 3 - Rinomanometria anterior modificada: instrumentação para estimar a área nasofaríngea (ANF) (Sistema PERCI-SARS, Microtronics Corp., Carrboro, NC, USA) 
Valores controles

No caso da área nasal medida por rinomanometria posterior, foram considerados como limites normais os valores estabelecidos por Dalston et al (1992) apresentados no quadro 2A - anexo 4. Valores inferiores a estes limites foram considerados como sugestivos de obstrução nasal.

No caso da área nasofaríngea, foram considerados como valores controles os estabelecidos por Sampaio et al (1997) mostrados no quadro 3A anexo 4.

Variações individuais entre as medidas pré e pós-operatórias foram consideradas significativas do ponto de vista clínico quando superiores a $10 \%$ do valor pré-operatório, que corresponde à margem de erro do método conforme preconizado por Watzke et al (1990).

\subsection{Estatística}

Para as variáveis quantitativas, a significância das diferenças entre amostras independentes (grupo CQ vs. grupo SQ) foi analisada pelo teste paramétrico $t$ de Student. A significância das diferenças entre amostras relacionadas (valores PRE vs. POS1; PRE vs. POS2 e POS1 vs. POS2) foi analisada pelo teste paramétrico t pareado. Para as variáveis qualitativas, a significância das diferenças entre os grupos CQ e SQ foi analisada pelo teste exato de Fisher (Zar 1996). Foram aceitos como significantes os valores de $\mathrm{p}<0,05$. 


\section{RESULTADOS.}

Foi analisado um total de 58 pacientes antes da cirurgia (PRE), sendo que 51 realizaram a primeira avaliação pós-operatória (POS1) e todos os 58 pacientes realizaram a segunda avaliação pós-operatória (POS2). Na análise dos resultados essa diferença no tamanho da amostra foi levada em consideração. Os resultados individuais obtidos estão apresentados nas tabelas $2 \mathrm{~A}$ a $8 \mathrm{~A}$ do anexo 5, incluindo queixas respiratórias e valores individuais de ANp, ANa, ANF e diferenças pré e pós-operatórias em cada caso analisado.

\subsection{Análise das queixas respiratórias.}

Em POS1, verificou-se que 55\% (28/51) dos pacientes passaram a relatar queixas respiratórias, que não apresentavam antes da faringoplastia. Conforme mostrado na tabela 3 , foram observadas as seguintes condições: apenas respiração oral $(n=5)$; apenas ronco $(n=20)$; dificuldade respiratória durante o sono $(n=2)$; respiração oral + ronco + dificuldade respiratória no sono $(n=1)$. Há que se ressaltar que 1 paciente foi excluído do grupo $C Q$ por apresentar obstrução acompanhada de queixas de tal magnitude que necessitou ser submetido à ressecção do retalho faríngeo. Em outro caso (paciente 4) não foi possível realizar a avaliação da área nasal no POS1, uma vez que o paciente apresentava obstrução grave a ponto de não conseguir manter a respiração nasal necessária para a realização do exame, o que só foi possivel na segunda avaliação pós-cirúrgica.

Em POS2, a proporção de pacientes que relataram queixas respiratórias diminuiu para $36 \%(21 / 58)$, sendo estas do tipo: apenas respiração oral $(n=4)$, apenas ronco $(n=15)$, respiração oral + ronco $(n=2)$, conforme mostrado na 
Tabela 3 - Número e porcentagem de pacientes que passaram a apresentar queixas respiratórias na primeira $(\mathrm{POS} 1)$ e na segunda avaliação póscirúrgica (POS2).

\begin{tabular}{ccc}
\hline QUEIXAS & POS1 & POS2 \\
\hline RO & 5 & 4 \\
RRS & 20 & 15 \\
RO+R & 2 & 0 \\
RO+R+DRS & 0 & 2 \\
\hline $\begin{array}{c}\text { Pacientes } \\
\text { Com queixas } \\
\text { Total de } \\
\text { pacientes } \\
\text { \% de pacientes } \\
\text { com queixas }\end{array}$ & 1 & 0 \\
\hline
\end{tabular}

$\mathbf{R O}=$ respiração oral

$\mathbf{R}=$ ronco durante o sono

DRS = dificuldade respiratória durante o sono 
tabela 3. Nesta fase, nenhum paciente referiu dificuldade respiratória durante o sono.

Com base nas observações aferidas em POS2, por ocasião do término do estudo, os 21 pacientes com queixas respiratórias após a faringoplastia passaram a compor o grupo CQ, e os demais 37 pacientes passaram a compor o grupo $S Q$, sem queixas respiratórias após a cirurgia.

\subsection{Análise dos valores médios da área nasal.}

A tabela 4 mostra os valores médios da área nasal medida por rinomanometria posterior (ANp) e anterior (ANa) em PRE, POS1 e POS2 nos grupos CQ e SQ. Verificou-se que, antes da cirurgia, a ANp foi de $0,465 \pm 0,138 \mathrm{~cm}^{2}$ no grupo CQ e de $0,523 \pm 0,174 \mathrm{~cm}^{2}$ no grupo SQ, em média. Após a cirurgia, a ANp foi de $0,373 \pm 0,164 \mathrm{~cm}^{2}$ em POS1 e $0,335 \pm 0,170 \mathrm{~cm}^{2}$ em POS2 no grupo CQ. No grupo SQ, a ANp foi de $0,436 \pm 0,141 \mathrm{~cm}^{2}$ em POS1 $0,461 \pm 0,183 \mathrm{~cm}^{2}$ em POS2. A análise estatística mostrou que os valores em POS1 e POS2 foram significantemente menores que os observados em PRE nos dois grupos estudados. Não houve diferença estatisticamente significante entre os valores de POS1 e POS2 nos dois grupos estudados. Os resultados obtidos estão ilustrados na figura 4.

A tabela 4 mostra, também, que, antes da cirurgia, a ANa foi de $0,469 \pm 0,135 \mathrm{~cm}^{2}$ no grupo CQ e de $0,585 \pm 0,166 \mathrm{~cm}^{2}$ no grupo SQ. Após a cirurgia, a ANa foi de $0,499 \pm 0,171 \mathrm{~cm}^{2}$ em POS1 e de $0,509 \pm 0,188 \mathrm{~cm}^{2}$ em POS2 no grupo CQ. No grupo SQ, a $\mathrm{ANa}$ foi de $0,568 \pm 0,172 \mathrm{~cm}^{2}$ em POS1 e $0,604 \pm 0,205 \mathrm{~cm}^{2}$ em POS2. A análise estatística mostrou que os valores PRE, POS1 e POS2 não diferiram estatisticamente entre si, conforme ilustra a figura 5 e que os valores de ANa foram significantemente maiores que os de ANp. 
Tabela 4 - Valores médios ( \pm desvio padrão) da área de secção transversa mínima nasal aferida por rinomanometria posterior (ANp) e da área de secção transversa mínima nasal aferida por rinomanometria anterior (ANa), expressos em $\mathrm{cm}^{2}$, obtidos antes da cirurgia (PRE), na primeira (POS1) e na segunda avaliação pós-cirúrgica (POS2) e as diferenças entre os valores pré e pós-cirúrgicos, nos grupos com queixas (CQ) e sem queixas respiratórias (SQ).

\begin{tabular}{|c|c|c|c|}
\hline \multirow[b]{3}{*}{ Grupo } & \multicolumn{2}{|r|}{ ANp } & \multirow{2}{*}{$\frac{\mathbf{A N a}}{0,469 \pm 0,135}$} \\
\hline & PRE & $0,465 \pm 0,138$ & \\
\hline & & & \\
\hline & POS1 & $0,373 \pm 0,164$ * & $0,499 \pm 0,171 \#$ \\
\hline & POS2 & $0,335 \pm 0,170 *$ & $0,509 \pm 0,188 \#$ \\
\hline \multirow[b]{2}{*}{ Grupo } & PRE & $0,523 \pm 0,174$ & $0,585 \pm 0,166 \# \S$ \\
\hline & & & \\
\hline & POS1 & $0,436 \pm 0,141$ * & $0,568 \pm 0,172 \#$ \\
\hline & POS2 & $0,461 \pm 0,183 * \S$ & $0,604 \pm 0,205 \#$ \\
\hline
\end{tabular}

diferença estatisticamente significante $(p<0.05)$

* PRE vs POS

\# ANp vs ANa

$\S$ grupo CQ vs grupo SQ 


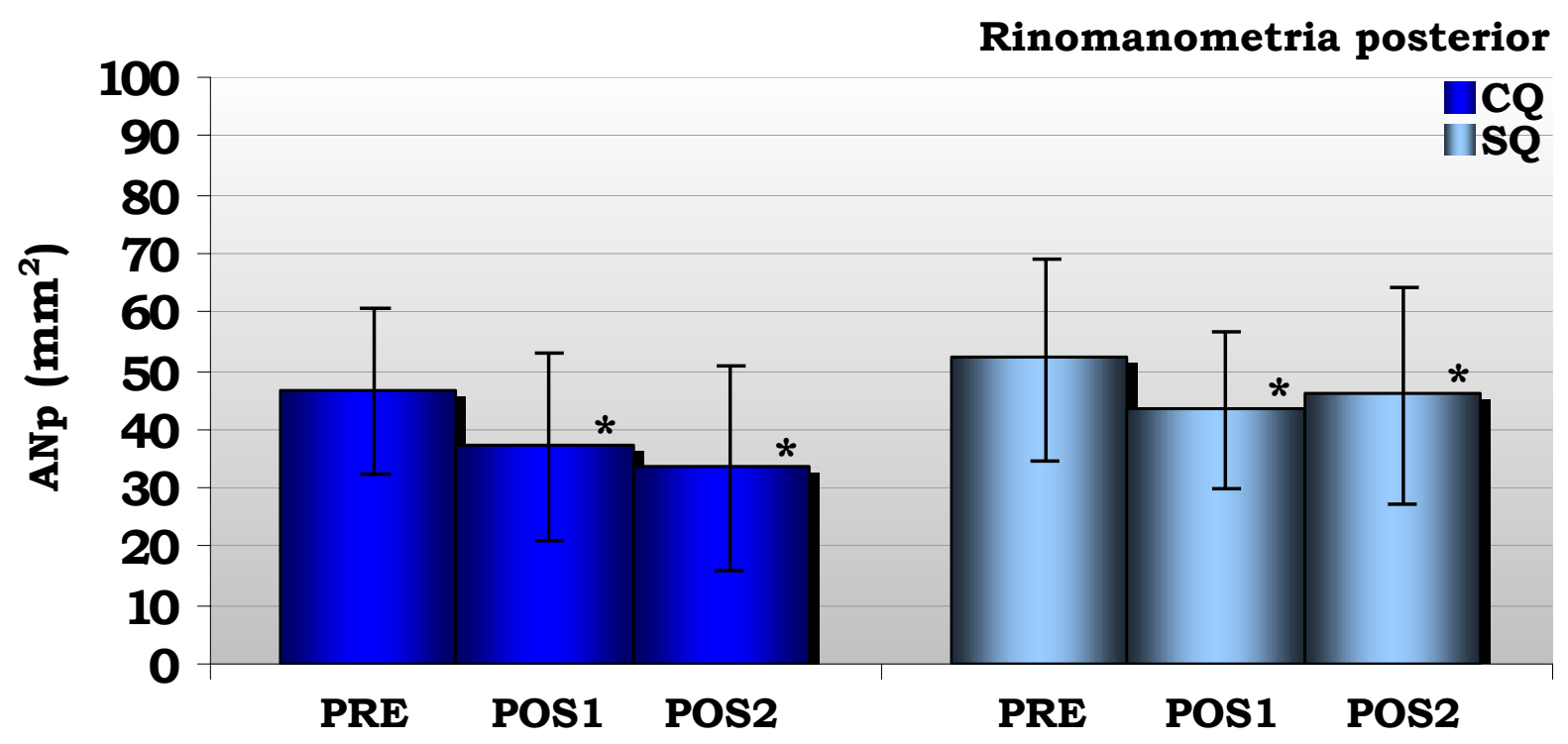

Figura 4 - Comparação entre os valores médios da área de secção transversa mínima nasal aferida por rinomanometria posterior (ANp) obtidos antes (PRE) da cirurgia, no primeiro pós-operatório (POS1) e no segundo pós-operatório (POS2) nos pacientes dos grupos com queixas (CQ) e sem queixas respiratórias (SQ). O asterisco $\left(^{*}\right)$ indica diferença estatisticamente significante entre os valores pré e pós-cirúrgicos. 


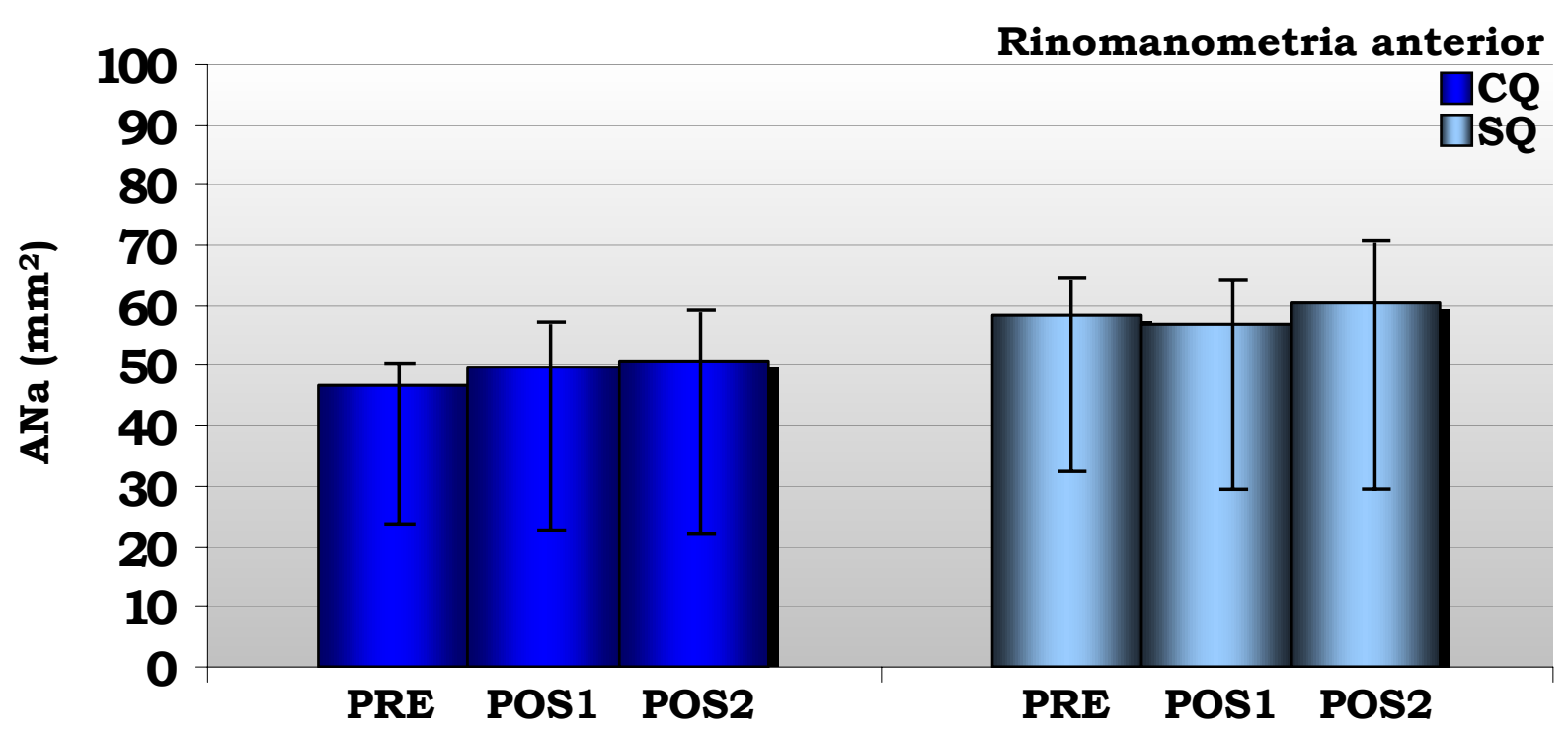

Figura 5 - Comparação entre os valores médios da área de secção transversa mínima nasal aferida por rinomanometria anterior (ANa) anterior obtidos antes (PRE) da cirurgia, no primeiro pós-operatório (POS1) e no segundo pós-operatório (POS2) nos pacientes dos grupos com queixas (CQ) e sem queixas respiratórias (SQ). 
Considerando esse resultado, aliás, esperado, as análises que se seguem foram feitas apenas para dados relativos a ANp.

A tabela 4 compara, ainda, as diferenças entre os grupos estudados. Observou-se que todos os valores obtidos no grupo CQ foram menores que os do grupo SQ, nas três etapas analisadas e nas duas técnicas de medida; contudo, diferenças estatisticamente significantes só foram observadas para os valores médios de ANp em POS2.

\subsection{Análise dos valores individuais da área nasal.}

Nas tabelas 3A e 4A do anexo 5 são apresentados os dados individuais da área nasal (ANp) aferida nos grupos CQ e SQ, respectivamente, nas quais os valores que se situaram abaixo dos limites normais estabelecidos por Dalston et al (1992) são assinalados com asterisco.

Conforme resume a tabela 5, no grupo CQ, observou-se que 9\% $(2 / 21)$ dos pacientes apresentava valores subnormais de ANp antes da cirurgia. Em POS1, 23\% (4/17) dos pacientes passaram a apresentar valores subnormais, aumentando esta proporção para 33\% (7/21) em POS2. Ressalte-se que em POS1, a proporção calculada não inclui os dois pacientes que não realizaram a avaliação por apresentar obstrução muito grave a ponto de impedir a realização do exame. Um desses pacientes foi excluído do estudo, o outro voltou a compor o grupo em POS2. Caso mantidos no estudo, a proporção real seria, portanto, de $31 \%(6 / 19)$ e $36 \%(8 / 22)$ respectivamente. No grupo SQ, a proporção foi de $14 \%(5 / 37)$ antes da cirurgia, aumentando para 30\% (10/33) em POS1 e para $38 \%(14 / 37)$ em POS2. As diferenças entre grupos não foram significantes. Esses resultados, ilustrados na figura 6, denotam que, a mesma proporção de pacientes dos grupos CQ e SQ apresentou valores subnormais após a cirurgia. 
Tabela 5 - Comparação entre a porcentagem de pacientes com valores subnormais da área de secção transversa mínima nasal aferida por rinomanometria posterior (ANp) antes da cirurgia (PRE), na primeira (POS1) e na segunda avaliação pós-cirúrgica (POS2), nos grupos com queixas (CQ) e sem queixas respiratórias (SQ).

\begin{tabular}{cccc}
\hline & \multicolumn{3}{c}{ ANp subnormal } \\
\hline & PRE & POS1 & POS2 \\
Grupo & $9 \%$ & $23 \%$ & $33 \%$ \\
CQ & $(2 / 21)$ & $(4 / 17)$ & $(7 / 21)$ \\
Grupo & $14 \%$ & $30 \%$ & $38 \%$ \\
SQ & $(5 / 37)$ & $(10 / 33)$ & $(14 / 37)$ \\
\hline
\end{tabular}

Diferenças entre CQ e SQ não significantes 


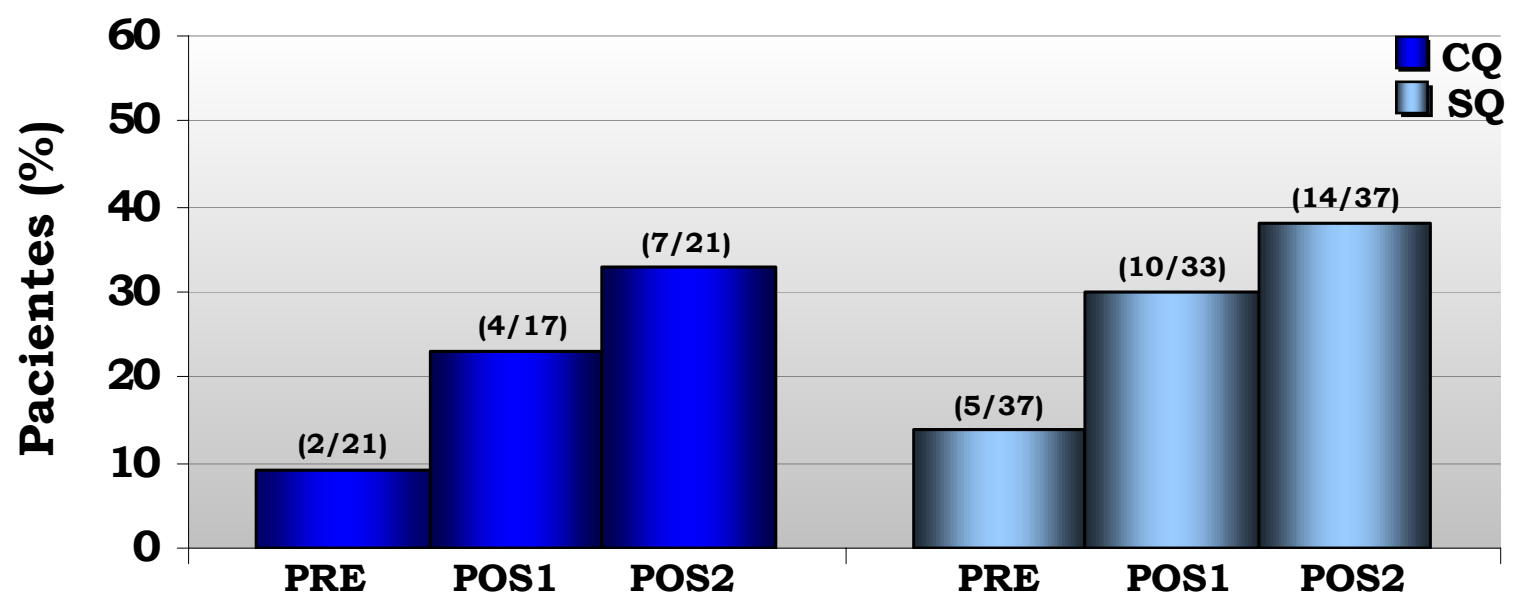

Figura 6 - Proporção de pacientes que apresentaram valores subnormais de ANp antes da cirurgia (PRE), na primeira avaliação pós-cirúrgica (POS1) e na segunda avaliação pós-cirúrgica (POS2) dos grupos com queixas (CQ) e sem queixas respiratórias (SQ). 


\subsection{Análise das variações individuais da área nasal.}

Ainda nas tabelas $3 \mathrm{~A}$ e $4 \mathrm{~A}$ do anexo 5 são apresentadas as diferenças entre as medidas pré e pós-operatórias e assinaladas as consideradas significativas, ou seja, superiores a $10 \%$ do valor observado no PRE.

Conforme resume a tabela 6 , e a figura 7 verificou-se que $71 \%(12 / 17)$ dos pacientes do grupo CQ apresentaram redução significativa em POS1 e 81\% (17/21), em POS2. Em 12\% (2/17) dos pacientes verificou-se aumento da ANp no POS1 e em 14\% (3/21) no POS2. Em 18\% (3/17) dos pacientes não houve alterações significativas no POS1 e 5\% (1/21) no POS2. Analisando o grupo SQ, observou-se redução significativa da ANp em 58\% (19/33) dos pacientes no POS1 e em 54\% (20/37) no POS2. Em 21\% (7/33) dos pacientes observou-se aumento da ANp no POS1 e em 24\% (9/37) no POS2. Em 21\% (7/33) dos pacientes não houve mudança significativa no POS1 e em $22 \%(8 / 37)$ no POS2. A análise dos resultados mostrou que maior número de pacientes do grupo $C Q$ apresentaram redução significativa da área nasal após a cirurgia em POS1 e POS2, sendo a diferença estatisticamente significante apenas em POS2. Por outro lado, maior número de pacientes do grupo SQ apresentaram aumento da área nasal sendo as diferenças entre os grupos não significantes estatisticamente.

\subsection{Análise dos valores da área nasofaringea.}

$\mathrm{Na}$ tabela 5A e 6A do anexo 5 são apresentados os valores individuais da área nasofaringea aferidos nos grupos $\mathrm{CQ}$ e SQ, respectivamente. Com relação a esses dados, há que se considerar uma importante limitação do método empregado, que restringe a $0,800 \mathrm{~cm}^{2}$ todos as áreas maiores que este valor. Isto impede a determinação das médias dos grupos, assim como a 
Tabela 6 - Porcentagem de pacientes que apresentaram redução, aumento e valores inalterados da área de secção transversa mínima nasal aferida por rinomanometria posterior $(\mathrm{ANp})$ antes da cirurgia $(\mathrm{PRE})$, na primeira (POS1) e na segunda avaliação pós-cirúrgica (POS2), nos grupos com queixas (CQ) e sem queixas respiratórias (SQ).

\begin{tabular}{|c|c|c|c|c|}
\hline & \multicolumn{4}{|c|}{ ANp } \\
\hline & & Redução & Aumento & Inalterado \\
\hline Grupo & POS1 & $\begin{array}{c}71 \% \\
(12 / 17)\end{array}$ & $\begin{array}{c}12 \% \\
(2 / 17)\end{array}$ & $\begin{array}{c}18 \% \\
(3 / 17)\end{array}$ \\
\hline $\mathbf{C Q}$ & POS2 & $\begin{array}{c}81 \% \\
(17 / 21)\end{array}$ & $\begin{array}{c}14 \% \\
(3 / 21)\end{array}$ & $\begin{array}{c}5 \% \\
(1 / 21)\end{array}$ \\
\hline Grupo & POS1 & $\begin{array}{c}58 \% \\
(19 / 33)\end{array}$ & $\begin{array}{c}21 \% \\
(7 / 33)\end{array}$ & $\begin{array}{c}21 \% \\
(7 / 33)\end{array}$ \\
\hline SQ & POS2 & $\begin{array}{c}54 \% \text { * } \\
(20 / 37)\end{array}$ & $\begin{array}{l}24 \% \\
(9 / 37)\end{array}$ & $\begin{array}{c}22 \% \\
(8 / 37)\end{array}$ \\
\hline
\end{tabular}

* diferença estatisticamente significante - CQ vs. SQ 


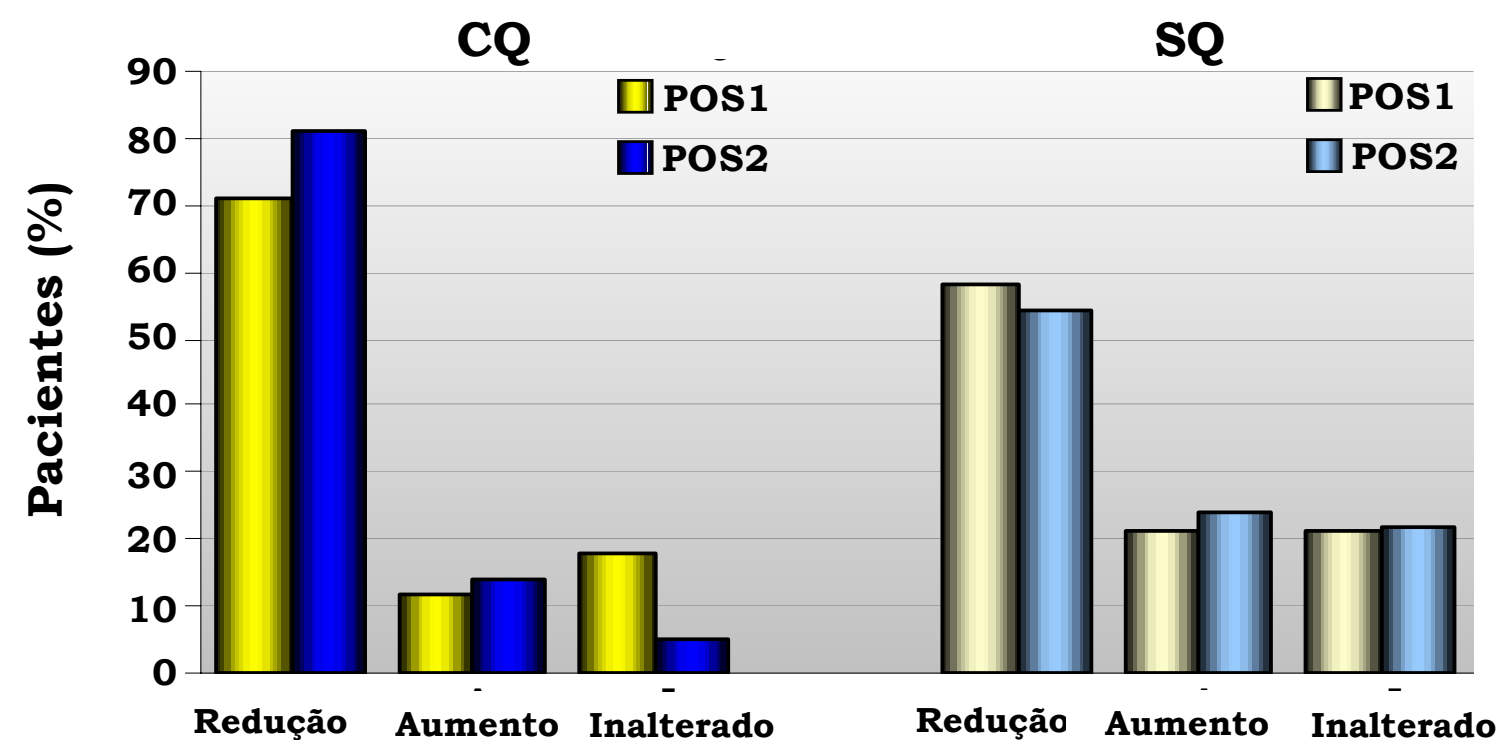

Figura 7 - Variações individuais da área de secção transversa mínima nasal aferida por rinomanometria posterior ANp observadas antes da cirurgia (PRE), na primeira avaliação pós-cirúrgica (POS1) e na segunda avaliação pós-cirúrgica (POS2), nos grupos com queixas (CQ) e sem queixas respiratórias (SQ). 
determinação de limites normais pelos métodos estatísticos convencionais, que dependem do valor da média, e, a análise das variações individuais pósoperatórias, uma vez que o valor $0,800 \mathrm{~cm}^{2}$ não corresponde à exata dimensão da nasofaringe. Entretanto, para fins exclusivos de confirmação dos resultados obtidos com as medidas de ANp e ANa, as médias de ANF foram calculadas para os grupos CQ e SQ, considerando como reais os valores de $0,800 \mathrm{~cm}^{2}$. Assim procedendo, verificou-se que, antes da cirurgia, todos os pacientes apresentaram ANF iguais a $0,800 \mathrm{~cm}^{2}$, exceto um paciente do grupo CQ que apresentou área igual a $0,553 \mathrm{~cm}^{2}$; neste caso a ANF "média" foi de $0,788 \pm 0,054 \mathrm{~cm}^{2}$. No grupo SQ todos apresentaram valores iguais a $0,800 \mathrm{~cm}^{2}$, equivalendo a uma "média" hipotética de $0,800 \pm 0,000 \mathrm{~cm}^{2}$. Na mesma linha de raciocinio, no grupo CQ, a "média" foi de $0,480 \pm 0,213 \mathrm{~cm}^{2}$ em POS1 e $0,536 \pm 0,264 \mathrm{~cm}^{2}$ em POS2. No grupo SQ, a "média" foi de $0,644 \pm 0,173 \mathrm{~cm}^{2} \mathrm{em}$ POS1 e de $0,682 \pm 0,168 \mathrm{~cm}^{2}$ em POS2. A grosso modo, portanto, esses resultados foram similares aos observados para a ANp, ou seja, redução dos valores em POS1 e POS2, mais pronunciada no grupo CQ.

Nas tabelas 5A e 6A do anexo 5 são também destacados com asterisco, os dados individuais de ANF dos grupos CQ e SQ, respectivamente, que se situaram abaixo do valor adotado como referência $\left(0,500 \mathrm{~cm}^{2}\right)$. Esse valor foi estipulado para fins de simplificação e para possibilitar a interpretação dos dados, a partir da observação que crianças e adultos normais apresentaram um valor mínimo de $0,570 \mathrm{~cm}^{2}$ em estudo realizado em nosso laboratório (Sampaio et al 1997 quadro 3A - anexo 4). Esse procedimento se fez necessário dada a limitação da técnica que impede o cálculo dos valores limites normais para essa variável. 
A análise desses dados mostrou que nos grupos CQ e SQ, nenhum paciente apresentava valores de ANF abaixo do valor de referência antes da cirurgia. Conforme resume a tabela 7 , em POS1, 59\% (10/17) dos pacientes do grupo CQ passaram a apresentar valores "subnormais", e, 33\% $(7 / 21) \mathrm{em}$ POS2. No grupo SQ, a proporção foi de 24\% (8/33) em POS1 e 16\% (6/37) em POS2. Assim, diferentemente do observado para a ANp, e de acordo com o esperado, maior proporção de valores "subnormais" foram observados no grupo CQ após a cirurgia. Para melhor visualização desses resultados, a distribuição dos pacientes segundo a área nasofaringea em POS2 é mostrada na figura 8.

Pelas razões já expostas não foi possivel realizar a análise das variações individuais da área nasofaringea, como feito para a área nasal. 
Tabela 7 - Comparação entre a porcentagem de pacientes com valores subnormais da área de secção transversa mínima nasofaríngea (ANF) aferida por rinomanometria anterior modificada antes da cirurgia (PRE), na primeira (POS1) e na segunda avaliação pós-cirúrgica (POS2), entre os grupos com queixas (CQ) e sem queixas respiratórias (SQ).

\begin{tabular}{cccc}
\hline & \multicolumn{3}{c}{ ANF subnormal } \\
& PRE & POS1 & POS2 \\
Grupo & & $59 \%$ & $33 \%$ \\
CQ & $0 \%$ & $(10 / 17)$ & $(7 / 21)$ \\
Grupo & & $24 \% *$ & $16 \%$ \\
SQ & $0 \%$ & $(8 / 33)$ & $(6 / 37)$ \\
\hline
\end{tabular}

* diferença estatisticamente significante - CQ vs. SQ 


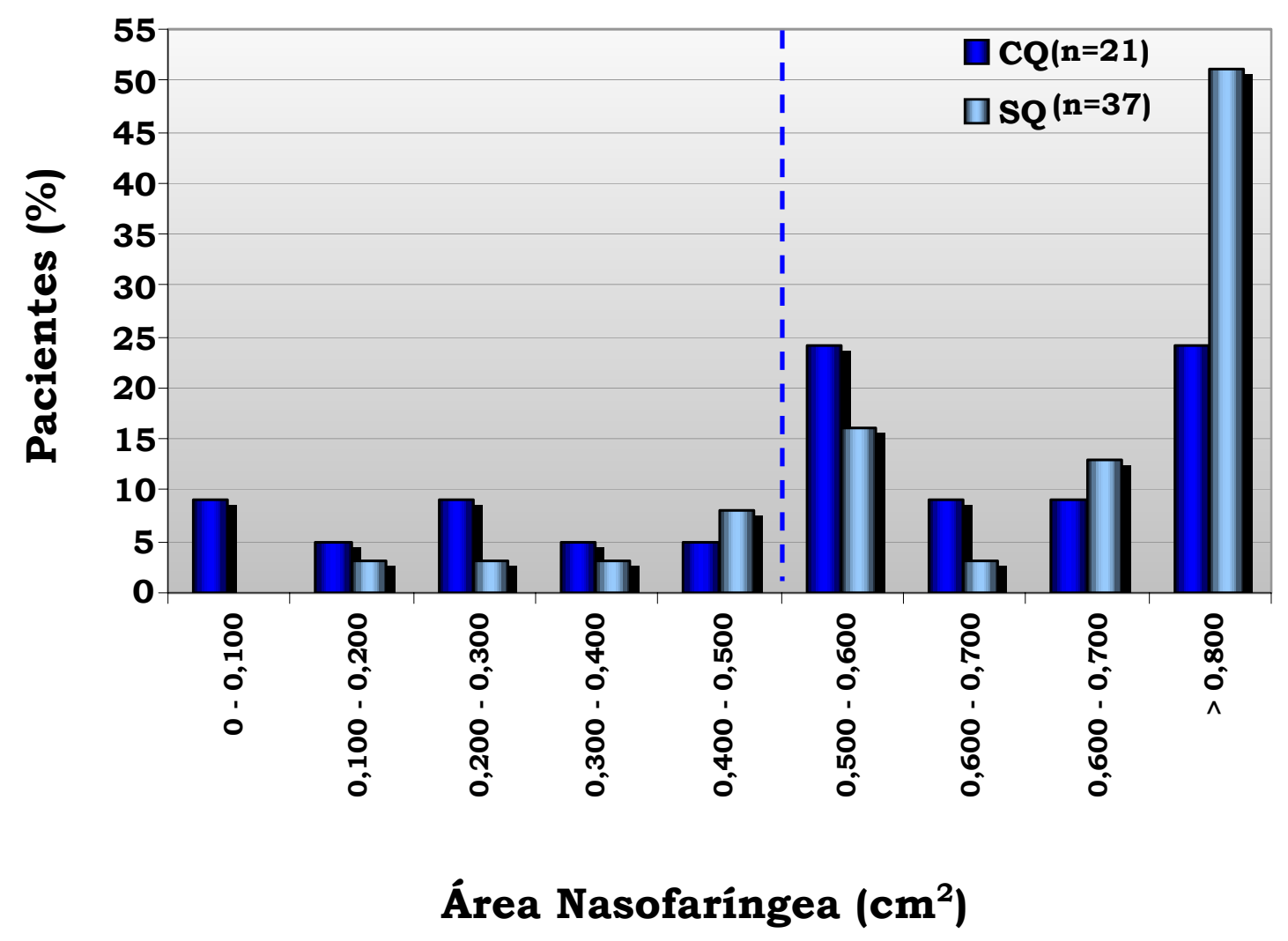

Figura 8 - Distribuição dos pacientes dos grupos com queixas (CQ) e sem queixas respiratórias (SQ) quanto à área de secção transversa nasofaríngea (ANF) aferida na segunda avaliação pós-cirúrgica (POS2). 


\section{DISCUSSÃO.}

Considerando que o retalho faríngeo é a técnica cirúrgica mais utilizada na correção da IVF, principalmente nos casos mais graves, e que, por outro, lado é a técnica que parece estar mais associada a complicações respiratórias pós-cirúrgicas (Sloan 2000), o presente estudo teve como objetivo quantificar a freqüência de aparecimento de queixas respiratórias após a cirurgia e correlacionar esses achados com a magnitude da redução das dimensões nasofaringeas determinada pelo retalho. Utilizou-se, para tanto, uma abordagem fisiológica a partir da qual são estimadas as dimensões internas nasais, ou seja, a área de secção transversa mínima existente para a passagem do fluxo de ar respiratório, por meio da medida de pressões e fluxos gerados no trato vocal durante a respiração nasal (rinomanometria posterior). Para fins de comparação foram, também, feitas, medidas compartimentalizadas da cavidade nasal (rinomanometria anterior) e da nasofaringe (rinomanometria anterior modificada), separadamente.

Quanto às queixas respiratórias o que se observou foi uma elevada prevalência no grupo de pacientes estudado. Na primeira avaliação pósoperatória realizada ( 5 meses após a cirurgia, em média), verificamos que 55\% dos pacientes passaram a relatar sintomas como respiração oral, ronco noturno e sensação de obstrução respiratória durante o sono. Segundo a literatura, estes sintomas são esperados após a faringoplastia. Hairfield et al (1988), por exemplo, reportaram que o retalho faringeo aumenta a prevalência de respiração oral em pacientes fissurados. Shprintzen (1988) afirmou que o ronco é uma das complicações pós-operatórias mais freqüentes na cirurgia de retalho faringeo. Wells et al (1999) afirmaram que a obstrução respiratória noturna é um achado comum no período pós-operatório imediato e que se resolve na 
maioria dos casos. A prevalência de sintomas respiratórios após a faringoplastia relatada na literatura é bastante variável. Alguns autores as descreveram em 4 a 10\% dos casos (Thurston et al 1980, Shprintzen 1988, Pensler e Reich 1991, Ysunza et al 1993, Valnicek et al 1994 e Wells et al 1999), outros relataram proporções entre 16 a 20\% (Orr et al 1987 e Peña et al 2000) e outros, ainda, em proporções maiores que variam de 35 a 92\% (Velasco et al 1988, Sirois et al 1994, Lesavoy et al 1996, Zuiani et al 1998 e Liao et al 2002), faixa onde se situa o presente estudo. Diferenças nas técnicas cirúrgicas, habilidade de cirurgiões, métodos de avaliação e queixas analisadas podem ser algumas das razões para explicar as diferenças de prevalência encontradas.

É importante ressaltar que na avaliação pré-operatória, 65\% dos pacientes já relatavam respiração oral ou ronco noturno, confirmando dados da literatura de Hairfield e Warren (1989) e, Warren et al (1990), os quais mostraram que aproximadamente $60 \%$ da população de indivíduos fissurados de lábio e palato apresentam vias aéreas inadequadas para a respiração nasal normal. Há que se enfatizar que no presente estudo foi considerado como "aparecimento de queixas respiratórias no pós-operatório" somente a situação em que o paciente relatava piora da respiração após a cirurgia ou quando passava a relatar queixas antes inexistentes.

A longo prazo, a proporção de pacientes com queixas respiratórias diminuiu para $36 \%$, ou seja, pacientes que se queixaram de dificuldades respiratórias na primeira avaliação pós-operatória realizada, deixaram de apresentá-las na segunda avaliação (14 meses após a cirurgia, em média). Em 2 casos, os pacientes passaram a relatar outras queixas, além daquelas que já haviam relatado. 
Os sintomas observados, ao menos no primeiro pós-operatório, podem ser decorrentes de edema na nasofaringe causada pelo ato cirúrgico. De acordo com Wells et al (1999) a obstrução precoce das vias aéreas superiores após a faringoplastia é, com freqüência, decorrente desse efeito que desaparece ao longo do tempo com a completa cicatrização do retalho. Os achados do presente trabalho demonstram que este não foi o único fator envolvido, uma vez que, a longo prazo um grupo considerável de pacientes ainda apresentava sintomas obstrutivos. Parece provável que ao efeito inicial do edema tenha se somado a sobrecorreção da IVF pela construção de um retalho excessivamente largo, muito embora Liao et al (2002), por exemplo, não tenham observado correlação entre a largura do retalho e a incidência e gravidade de apnéia obstrutiva do sono.

Independente da causa determinante das queixas, se resultantes de edema ou de sobrecorreção, dois casos com obstrução nasofaringea grave devem ser destacados da amostra de casos aqui analisados. Primeiro, em um deles, houve necessidade da ressecção total do retalho faringeo, pois, imediatamente após a cirurgia a paciente passou a se queixar de respiração oral obrigatória, falta de ar, ronco noturno intenso e graves dificuldades respiratórias durante o sono, necessitando, inclusive, dormir sentada. Relatava, ainda, sonolência excessiva, cansaço constante e problemas de concentração durante o dia, sintomas que refletem inequivocamente a presença de um retalho obstrutivo levando à apnéia noturna. Neste caso a cirurgia para retirada do retalho faringeo foi realizada 20 dias após a faringoplastia. Outro paciente apresentou igualmente obstrução nasal grave impedindo a realização da rinomanometria após a cirurgia, situação que se reverteu parcialmente na segunda avaliação pós-cirúrgica. 
Os pacientes que não apresentaram queixas ao término do estudo (64\%) merecem comentário especial. Warren e Drake (1993) sugeriram que a construção do retalho pode ser mais prejudicial num indivíduo cuja via aérea é adequada antes da cirurgia do que em outro que apresenta certo grau de obstrução nasal previamente à cirurgia. Levantaram a possibilidade que o indivíduo com boa permeabilidade nasal certamente se aperceberia mais da obstrução que o já portador de obstrução nasal. Em sendo verdadeira essa possibilidade, esperariamos encontrar, antes da cirurgia, maior número de pacientes com dimensões nasais normais nos pacientes que relataram sintomas após a cirurgia. Em verdade, observou-se uma proporção apenas ligeiramente maior de pacientes do grupo CQ (91\%) que do grupo SQ (86\%) nessa condição. Considerando essa pequena diferença entre os dois grupos a questão fica ainda em aberto para futuros estudos.

Com relação ao efeito do retalho faríngeo sobre a área de secção transversa minima nasal aferida por rinomanometria posterior (ANp), verificou-se que a presença do retalho, tanto a curto quanto a longo prazo, levou a uma diminuição significativa do valor médio observado nos dois grupos estudados, sendo esta mais pronunciada no grupo CQ, de $28 \%$ em POS2, do que no grupo SQ (12\%), refletindo uma provável relação, ainda que pequena, entre o grau de obstrução produzido pelo retalho com o aparecimento de sintomas respiratórios após a cirurgia. Por outro lado, a área de secção transversa mínima nasal aferida por rinomanometria anterior (ANa) não se alterou com a presença do retalho, em média. Este último resultado veio a demonstrar que as variações observadas na medida feita com a rinomanometria posterior resultaram, de fato, de variações nas dimensões nasofaríngeas e não da cavidade nasal em si, o que obviamente não seria de se esperar com a colocação de retalho ao nível da nasofaringe. Confirmação adicional se obteve com a medida direta da área 
nasofaríngea, que por limitações técnicas, não pode ser avaliada isoladamente. Aliás, com relação a essa medida, a variação induzida pela cirurgia foi ainda mais evidente, assim como a diferença entre os grupos CQ e SQ. Vale ressaltar que as medidas feitas com a rinomanometria anterior, na qual a área bilateral é aferida pela soma algébrica das áreas direita e esquerda foram significativamente maiores que as medidas bilaterais determinadas pela rinomanometria posterior. Esse fato já foi descrito por Unno et al (1986) em indivíduos normais, justamente em função do fato da medida feita com a rinomanometria anterior não incorporar constrições eventuais ao nível da nasofaringe. Ao mesmo tempo isso poder ser uma evidência a mais da existência de obstrução significativa em porções mais posteriores da cavidade nasal.

Nossos achados confirmam os de Smith e Guyette (1993) que avaliaram separadamente a resistência das cavidades nasais direita e esquerda, a resistência da nasofaringe, da área nasal bilateral (direita + esquerda) e da via aérea nasal total (todos os componentes) em 2 pacientes submetidos à cirurgia de retalho faríngeo. Verificaram, 6 a 7 semanas após a cirurgia, um aumento da resistência da via aérea nasal total atribuído em $70 \%$ a $90 \%$ ao aumento da resistência da nasofaringe. Aos 7-10 meses observaram decréscimo substancial da resistência nasofaringea nos dois pacientes (para níveis normais em um dos casos).

A real importância da redução das dimensões nasofaringeas determinada pela faringoplastia nos pacientes do presente estudo pode ser melhor julgada por outras duas abordagens de análise. Primeiro, a partir da comparação dos valores individuais alcançados no pós-operatório com valores normais de referência. No caso da área avaliada por rinomanometria posterior, observou-se aumento na proporção de pacientes com áreas abaixo do mínimo 
aceitável como normal por Dalston et al (1992), para os quais, portanto, houve o que podemos chamar de sobrecorreção, ou seja, diminuição além do esperado da nasofaringe. Contudo, neste caso em particular, isso se deu tanto no grupo CQ como no SQ, sugerindo, a princípio, não haver a esperada relação entre o grau de redução determinado pelo retalho e o aparecimento de sintomas respiratórios. Entretanto, na análise direta da área nasofaringea comparativamente a um valor de referência definido a partir de estudo realizado em nosso laboratório (Sampaio et al 1997), o grupo CQ diferiu uma vez mais do grupo SQ, sendo que agora a proporção de valores "subnormais" observados após a cirurgia, que se mostrou significativamente maior no grupo $\mathrm{CQ}$, confirmando mais uma vez a relação entre as dimensões pós-operatórias da nasofaringe e o aparecimento de queixas. Sob outro ponto de vista, maior proporção de pacientes do grupo SQ apresentaram valores normais no préoperatório. Não foi possivel, entretanto, identificar um valor mínimo da área nasofaringea pós-operatória a partir do qual os pacientes passaram a apresentar sintomas de obstrução. A análise da distribuição dos valores na figura 8 mostrou que em baixos valores (áreas reduzidas) se situaram também pacientes sem sintomas. Considerando que nestes casos a esperada mudança do modo nasal de respiração para o oral (Warren et al 1990) não ocorreu para compensar a obstrução nasal propiciada pelo retalho, é de se considerar a possibilidade aventada por Warren e Drake (1993) de que estes pacientes apresentavam já antes da cirurgia o nariz obstruído e respiração oral.

Numa segunda abordagem, a análise das variações individuais da área nasal, observou-se que o retalho faringeo teve um efeito variável produzindo reduções, aumentos ou mantendo inalteradas as medidas no pós-operatório. Como esperado, em função da construção do retalho, na maioria dos pacientes foram observadas reduções da área nasal, sendo que isso ocorreu em maior 
proporção nos pacientes do grupo CQ. Em contrapartida, maior proporção de pacientes do grupo SQ apresentou aumento da área nasal ou valores inalterados, o que explica, pelo menos em parte, o não aparecimento de sintomas.

A ocorrência de aumentos da área nasal após a faringoplastia parece, a princípio, um efeito paradoxal. Resultados semelhantes foram encontrados por Witsell et al (1994) em 2 de 7 pacientes avaliados em estudo preliminar. Os autores não encontraram explicação para o resultado observado, mas sugeriram que esse tipo de variação poderia ser decorrente de alguma alteração no grau de hipertrofia de conchas ou da tonsila faríngea. Isso se confirmou no presente estudo ao analisarmos a área nasal por rinomanometria anterior, procedimento não usado por aqueles autores e que afere as dimensões internas da cavidade nasal, exclusivamente. Verificou-se que em todos os 12 pacientes dos grupos CQ e SQ em que houve aumento de área nasal medida por rinomanometria posterior, ocorreu também aumento da área medida por rinomanometria anterior, sem redução concomitante da área nasofaríngea (exceto em 3 casos). Esses achados demonstram que a variação para mais, se deveu, de fato, a uma melhora da permeabilidade nasal não relacionada à faringoplastia. É possível que estes pacientes apresentassem certo grau de obstrução nasal funcional, não identificada na avaliação pré-operatória, que se modificou no intervalo de tempo entre as avaliações pré e pós-operatórias.

É preciso, finalmente, analisar as variações que se processaram ao longo do tempo. Com relação às queixas respiratórias, como já discutido, o que se observou foi uma nítida redução de sua prevalência da primeira para a segunda avaliação pós-operatória (de 55\% para 36\%). Analisando mais detalhadamente, essa redução se deveu a uma pequena diminuição na proporção de pacientes com ronco noturno (de 21 para 17 pacientes) e ao desaparecimento do relato de 
obstrução respiratória durante o sono em 3 pacientes que dela se queixaram na primeira avaliação. A proporção de pacientes com respiração oral após a cirurgia, por sua vez, não se alterou. Com relação às medidas rinomanométricas, variações dignas de nota se deram com relação à proporção de pacientes com área nasofaríngea "subnormal", que diminuíram consideravelmente da primeira para a segunda avaliação; essa diminuição do efeito obstrutivo do retalho explica, portanto, a redução de sintomas. No entanto, há que se enfatizar que, contrariamente ao que afirmaram autores como Wells et al (1999), os sintomas respiratórios não desapareceram por completo ao longo do tempo, o que tem importante significado clínico. Em termos aerodinâmicos, o ronco é um sintoma esperado após o estreitamento da nasofaringe pelo retalho (Cole 1993). Mas, ao mesmo tempo, o ronco pode ser um sinal indicativo de apnéia obstrutiva do sono, muitas vezes despercebida pelo paciente, de modo que o relato de ronco não pode ser subestimado; ao contrário, no paciente submetido à faringoplastia, o aparecimento do ronco deve ser necessariamente explorado em maiores detalhes por meio de levantamento minucioso da história clínica, o qual, sempre que possível, deve vir acompanhado de um estudo polissonográfico que permite o efetivo diagnóstico da apnéia obstrutiva do sono e da conseqüente hipóxia. Os achados recentes de Liao et al (2002) justificam essa preocupação, uma vez que esse distúrbio foi observado em $90 \%$ dos casos analisados após 6 meses de cirurgia.

Em suma, os resultados obtidos no presente estudo nos fazem rejeitar a afirmação de Levine (1996), ao comentar resultados do estudo de Lesavoy et al (1996), de que a obstrução de vias aéreas no pós-operatório imediato deve ser vista mais como uma seqüela freqüente (e transitória) do que como uma complicação da cirurgia de retalho faríngeo. Ao contrário, em nosso estudo prospectivo, o que se observou foi a persistência de sintomas a longo prazo em 
parcela considerável dos pacientes, relacionada à diminuição permanente, além do esperado e do aceitável, das dimensões da região nasofaringea. Por outro lado, nossos achados nos fazem concordar com Bardach (1995) ao afirmar que, por vezes, o restabelecimento de uma respiração adequada deve ser priorizado relativamente ao objetivo principal da faringoplastia, a correção da fala, em função dos graves prejuízos trazidos pela hipóxia crônica que resulta da presença de um retalho obstrutivo. 


\section{CONCLUSÕES.}

Em pacientes submetidos à cirurgia de retalho faríngeo para a correção de insuficiência velofaríngea:

1) O levantamento da história clínica mostrou o aparecimento ou agravamento de queixas respiratórias (respiração oral, ronco e sensação de obstrução respiratória no sono) em parcela significativa dos casos analisados ( $55 \%$ a curto prazo e $36 \%$ a longo prazo).

2) A rinomanometria mostrou redução das dimensões nasofaríngeas em parcela considerável dos casos, a curto e longo prazo, para niveis subnormais em alguns deles.

3) A redução das dimensões nasofaríngeas se mostrou mais acentuada nos pacientes que relataram queixas respiratórias após a cirurgia.

4) As queixas e o efeito do retalho sobre as dimensões nasofaringeas se atenuaram ao longo do tempo, sem, contudo, desaparecer por completo em alguns casos.

Considerando que as queixas respiratórias apresentadas pelos pacientes podem refletir uma condição subjacente de hipóxia crônica, essa possibilidade deve ser considerada quando da indicação de uma faringoplastia de retalho para a correção dos sintomas de fala decorrentes da insuficência velofaringea. Assim, também, é mandatório o acompanhamento dos resultados cirúrgicos por meio de métodos objetivos, de modo que providências possam ser tomadas para evitar os efeitos deletérios da presença de um retalho obstrutivo na nasofaringe. 


\section{REFERÊNCIAS BIBLIOGRÁFICAS.}

Abramson DL, Marrinan EM, Mulliken JB. Robin sequence: obstrutive sleep apnea following pharyngeal flap. Cleft Palate Craniofac J 1997; 34:256-60.

Altmann EBC. Anatomia e fisiologia do esfincter velofaringeo. In: Altmann EBC, editora. Fissuras labiopalatinas. 2a ed. Carapicuiba: Pró-Fono; 1997. p.133-56.

Argamaso RV, Shprintzen RJ, Strauch B, Lewin ML, Daniller AI, Ship AG, et al. The role of lateral pharyngeal wall movement in pharyngeal flap surgery. Plast Reconstr Surg 1980; 66:214-9.

Aronson AE. Nasal resonatory disorders. In: Aronson AE, editors. Clinical voice disorders: an interdisciplinary approach. New York: Thieme; 1985. p.199-247.

Bardach J. Secondary surgery for velopharyngeal insufficiency. In: Shprintzen RJ, Barbach J, editors. Cleft palate speech management: a multidisciplinary approach. St. Louis: Mosby; 1995. p.277-94.

Bradley DP. Congenital and acquired velopharyngeal inadequacy. In: Bzoch KR, editors. Communicative disorders related to cleft lip and palate. 3th ed. Boston: Little-Brown; 1989. p.106-22.

Brondsted K, Liisberg WB, Orsted A, Prytz S, Fogh-Andersen P. Surgical and speech results following palatopharyngeal operations in Denmark 1959-1977. Cleft Palate $J$ 1984; 21:170-9.

Brown AS, Cohen MA, Randall P. Levator muscle reconstruction: does it make a difference? Plast Reconstr Surg 1983; 72:1-8. 
Butow KW, Jacobs FJ. Intravelar veloplasty: surgical modification according to anatomical defect. Int J Oral Maxillofac Surg 1991; 20:296-300.

Bzoch KR. The effects of a specific pharyngeal flap operation upon the speech of forty cleft palate persons. J Speech Hear Dis 1964; 29:111-20.

Bzoch KR. Measurement and assessment of categorial aspects of cleft palate language, voice, and speech disorders. In: Bzoch KR, editors. Communicative disorders releted to cleft lip and palate. 3th ed. Boston: Little-Brown; 1989. p.137-73.

Caouette-Laberge L, Egerszegi EP, de Remont AM, Ottenseyer I. Long-term follow-up after division of a pharyngeal flap for severe nasal obstruction. Cleft Palate Craniofac J 1992; 29:27-31.

Cole P. The respiratory role of the upper airway. St Louis: Mosby Year Book; 1993.164p.

Croft CB, Shprintzen RJ, Rakoff SJ. Patterns of velopharyngeal valving in normal and cleft palate subjects: a multi-view videofluoroscopic and nasoendoscopic study. Layngoscope 1981; 91:265-71.

D'Antonio LL. Evaluation and management of velopharyngeal dysfunction: a speech pathologist's viewpoint. Probl Plast Recontr Surg 1992; 2:86-111. 
D'Antonio LL, Scherer NJ. The evaluation of speech disorders associated with clefting. In: Shprintzen RJ, Bardach J. editors. Cleft palate speech management: a multidisciplinary approach St. Louis: Mosby-Year Book; 1995. p 176-220.

Dalston RM. Position paper regarding standards of care for patients with craniofacial anomalies. Presented at the American Cleft Palate-Craniofacial Association Consensus Conference, Pittsburgh, Pennsylvania, May 2-5, 1991.

Dalston RM, Warren DW, Dalston ET. A preliminary study of nasal airway patency and its potential effect on speech performance. Cleft Palate Craniofac $J$ 1992; 29:330-5.

De Serres LM, Deleyiannis FWB, Eblen LE, Gruss JS, Richardson MA, Sie KCY. Results with sphincter pharyngoplasty and pharyngeal flap. Int $J$ Pediatr Otorhinolaryngol 1999; 48:17-25.

Dumbach J. Refinements of intravelar veloplasty. Scand J Plast Reconstr Surg $1987 ; 21: 103-7$.

Eufinger H, Bremerich A, Eggeling V, Gellrich NC. Speech results and velopharyngeal morphology following 151 cranially based velopharyngoplasties. Folia Phoniatr Logop 1995; 47:193-8.

Golding-Kushner KJ. Treatment of articulation and resonance disorders associated with cleft palate and VPI. In: Shprintzen RJ, Barbach J, editors. 
Cleft palate speech management: a multidisciplinary approach. St. Louis: Mosby; 1995. p.327-51.

Gomes PRM, Mélega JM. Tratamento cirúrgico. In: Altmann EBC, editora. Fissuras labiopalatinas. 2a. ed. Carapicuiba: Pró-Fono; 1997. p.61-72.

Gosain AK, Conley SF, Marks S, Larson DL. Submucous cleft palate: diagnostic methods and outcomes of surgical treatment. Plast Reconstr Surg 1996; 97:1497-509.

Graham WP 3d, Hamilton R, Randall P, Winchester R, Stool S. Complications following posterior pharyngeal flap surgery. Cleft Palate $J$ 1973; 10:176-80.

Hall CD, Golding-Kushner K, Argamaso RV, Strauch B. Pharyngeal flap surgery in adults. Cleft Palate Craniofac J 1991; 28:179-82.

Hairfield WM, Warren DW. Dimensions of the cleft nasal airway in adults: a comparison with subjects without cleft. Cleft Palate $J$ 1989; 26:9-13.

Hairfield WM, Warren DW, Seaton DL. Prevalence of mouthbreathing in cleft lip and palate. Cleft Palate $J$ 1988; 25:135-8.

Hirschberg J. Velopharyngeal insufficiency. Folia Phoniatr 1986; 38:221-76.

Hogan VM. A clarification of the surgical goals in cleft palate speech and the introduction of the lateral port control (L.P.C.) pharyngeal flap. Cleft Palate $J$ $1973 ; 10: 331-45$. 
Hogan VM, Sshwartz MF. Velopharyngeal incompetence. In: Converse JM, editors. Reconstructive plastic surgery: principles and procedures in correction, reconstruction and transplantation. 2nd.ed. Philadelphia: Saunders, 1977. p.2268-83.

Jackson P, Whitaker LA, Randall P. Airway hazards associated with pharyngeal flaps in patients who have the Pierre Robin syndrome. Plast Reconstr Surg $1976 ; 58: 184-6$.

Jorge JC. Influência da cirurgia de retalho faringeo na saturação de oxigênio arterial de indivíduos com fissura lábio-palatina [dissertação]. Bauru: Hospital de Reabilitação de Anomalias Craniofaciais; 2002.

Kaufman FL. Tratamento do paciente com fendas labial e palatina. Clin Pediat Am Norte 1991; 38:1187-207.

Kravath RE, Pollak CP, Borowiecki MD, Weitzman MD. Obstructive sleep apnea and death associated with surgical corection of velopharyngeal incompetence. $J$ Pediat 1980; 4:645-8.

Kummer AW, Curtis C, Wiggs M, Lee L, Strife J L. Comparison of velopharyngeal gap size in patients with hypernasality, hypernasality and nasal emission, or nasal turbulence (rustle) as the primary speech characteristic. Cleft Palate Craniofac J 1992; 29:152-6. 
Leanderson R, Korlof B, Nylén B, Eriksson G. The age and reduction of open nasality following superiorly based velo-pharyngeal flap operation in 124 cases. Scand J Plast Reconstr Surg 1974; 8:156-60.

Lesavoy MA, Borud LJ, Thorson T, Riegelhuth ME, Berkowitz CD. Upper airway obstruction after pharyngeal flap surgery. Ann Plast Surg 1996; 36:2630.

Levine NS. Invited discussion. Ann Plast Surg 1996; 36:31-2.

Liao YF, Chuang ML, Chen PKT, Chen NH, Yun C, Huang CS. Incidence and severity of obstructive sleep apnea following pharyngeal flap surgery in patients with cleft palate. Cleft Palate Craniofac J 2002; 39:312-6.

McWilliams BJ, Morris HL, Shelton RL. Cleft palate speech. Philadelphia: Decker; 1984.

Microtronics Corporation.: PERCI-PC System Manual. Chapel Hill; Microtronics; 1992.

Morris HI, Bardach J, Jones D, Christiansen JL, Gray SD. Clinical results of pharyngeal flap surgery: the Iowa experience. Plast Reconstr Surg 1995; 95:65262.

Orr WC, Levine NS, Buchanan RT. Effect of cleft palate repair and pharyngeal flap surgery on upper airway obstruction during sleep. Plast Reconstr Surg 1987; 80:226-30. 
Owsley Junior JQ, Lawson LI, Miller ER, Harvold EP, Chierici G, Blaskfield HM. Speech results from the high attached pharyngeal flap operation. Cleft Palate $J$ 1970; 7:306-17.

Peña M, Choi S, Boyajian M, Zalzai G. Perioperative airway complications following pharyngeal flap palatoplasty. Ann Otol Rhinol Laryngol 2000; 109:80811.

Pensler JM, Reich DS. A comparison of speech results after the pharyngeal flap and the dynamic sphincteroplasty procedures. Ann Plast Surg 1991; 26:441-3.

Riski JE, Ruff GGL, Georgiade GS, Barwick WJ, Edwards PD. Evaluation of the sphincter pharyngoplasty. Cleft Palate Craniofac J 1992; 29:254-61.

Rocha DL. Tratamento cirúrgico da insuficiência velofaríngica. In: Altmann EBC, editora. Fissuras labiopalatinas. 2a. ed. Carapicuiba: Pró-Fono; 1997. p.195-210.

Rocha DL. Tratamento cirúrgico da insuficiência velo-faringea com inclusão de silicone sólido na parede posterior da faringe [dissertação]. São Paulo: Faculdade de Medicina, Universidade de São Paulo; 1990.

Sampaio ACM, Trindade IEK, Genaro KF, Yamashita RP, Trindade Junior, AS. Dimensões das vias aéreas na respiração de repouso: áreas nasal e nasofaríngea. In: Livro de Resumos do I Congresso científico da pós-graduação do HPRLLP - USP; 1997 nov 28-29; Bauru, Brasil. São Paulo; 1997. p. 31. 
Schmelzeisen R, Hausamen JE, Laebell E, Hacki T. Long-term results following velopharyngoplasty with a cranially based pharyngeal flap. Plast Reconstr Surg 1992; 90:774-8.

Schulz R, Heller JC, Gens GW, Lewin M. Pharyngeal flap surgery and voice quality - factors related to success and failure. Cleft Palate $J$ 1973; 10:166-75.

Shprintzen RJ. Pharyngeal flap surgery and the pediatric upper airway. Int Anesthesiol Clin 1988; 26:79-88.

Shprintzen RJ, Lewin ML, Croft CB, Daniller AI, Argamaso RV, Ship AG, et al. A comprehensive study of pharyngeal flap surgery: tailor made flaps. Cleft Palate $J$ 1979; 16:46-55.

Sirois M, Caouette-Laberge L, Spier S, Larocque Y, Egerszegi P. Sleep apnea following a pharyngeal flap: a feared complication. Plast Reconstr Surg 1994; 5:943-7.

Skolnick ML, McCall GN, Barnes M. The sphincteric mechanism of velopharyngeal closure. Cleft Palate J 1973; 10:286-305.

Sloan GM. Posterior pharyngeal flap and sphinctr pharyngoplasty: the state of the art. Cleft Palate Craniofac J 2000; 37:112-22. 
Smith BE, Guyette TW. Component approach for partitioning nasal airway resistance: pharyngeal flap case studies. Cleft Palate Craniofac $J$ 1993; 30:7881.

Smith BE, Skef Z, Cohen M, Dorf DS. Aerodynamic assessment of the results of pharyngeal flap surgery: a preliminary investigation. Plast Reconstr Surg 1985; 76:402-10.

Smith JK, Huffman WC, Lierle DM, Moll KL. Results of pharyngeal flap surgery in patients with velopharyngeal incompetence. Plast Reconstr Surg 1963; 32:493-501.

Subtelny J, McCormack RM, Curtin JW, Subtelny JD, Musgrave KS. Speech, intraoral air pressure, nasal airflow - before and after pharyngeal flap surgery. Cleft Palate J 1970; 7:68-90.

Thurston JB, Larson DL, Shanks JC, Bennett JE, Parsons RW. Nasal obstruction as a complication of pharyngeal flap surgery. Cleft Palate J 1980; 2:148-54.

Trier WC. The pharyngeal flap operation. Clin Plast Surg 1985; 12:697-710.

Trindade IEK, Trindade Junior AS. Avaliação funcional da inadequação velofaríngea. In: Carreirão S, Lessa S, Zanini AS, editores. Tratamento das fissuras labiopalatinas. $2^{\text {a }}$ ed. Rio de Janeiro: Revinter; 1996. p. 223-35. 
Trindade IEK, Trindade Junior AS. A rinomanometria nas estenoses craniofaciais. In: Zanini SA, editor. Cirurgia craniofacial: malformações. Rio de Janeiro: Revinter; 2000. p.119-26.

Trost JE. Articulatory additions to the classical description of the speech of persons with cleft palate. Cleft Palate J 1981; 18:193-203.

Trost-Cardamone JE. Coming to terms with VPI: a response to Loney and Bloem. Cleft Palate J 1989; 26:68-70.

Unno T, Naitoh Y, Sakamoto N, Horikawa H. Nasal resistance measured by anterior rhinomanometry. Rhinology 1986; 24:49-55.

Valnicek SM, Zuker RM, Halpern LM, Roy WL. Perioperative complications of superior pharyngeal flap surgery in children. Plast Reconstr Surg 1994; 93:9548.

Van Demark DR, Hardin MA. Longitudinal evaluation of articulation and velopharyngeal competence of patients with pharyngeal flaps. Cleft Palate $J$ $1985 ; 22: 163-72$.

Velasco MG, Rivera AY, Primo ER, Nahas R. Sindrome de apnea obstructiva secundário a anomalías y cirugía de insuficiencia velofaringea. Cir Plast IberoLatinoam 1988; 3:165-71. 
Warren DW. Aerodynamic assessments and procedures to determine extent of velopharynngeal inadequacy. In: Bzoch KR, editors. Communicative disorders related to cleft lip and palate. $4^{\text {th }}$ ed. Austin: Pro-ed; 1997. p.411-37.

Warren DW. A quantitative technique for assessing nasal airway impairment. Am J Orthod 1984; 86:306-14.

Warren DW. Compensatory speech behaviors in individuals with cleft palate: a regulation/control phenomenon? Cleft Palate $J$ 1986; 23:251-60.

Warren DW, Drake AF. Cleft nose: form and function. Clin Plast Surg 1993; 20:769-79.

Warren DW, Drake AF, Davis JU. Nasal airway in breathing and speech. Cleft Palate Craniofac J 1992; 29:511-9.

Warren DW, Hairfield WM, Dalston ET. The relationship between nasal airway size and nasal-oral breathing in cleft lip and palate. Cleft Palate J 1990; $27: 46-51$.

Warren DW, Trier WC, Bevin AG. Effect of restorative procedures on the nasopharyngeal airway in cleft palate. Cleft Palate $J$ 1974; 11:367-73.

Watzke I, Turvey TA, Warren DW, Dalston R. Alterations in velopharyngeal function after maxillary advancement in cleft palate patients. $J$ Oral Maxillofac Surg 1990; 48:685-9. 
Wells $\mathrm{MD}, \mathrm{Vu} \mathrm{TA}$, Luce EA Incidence of nocturnal respiratory obstruction following posterior pharyngeal flap surgery. Ann Plast Surg 1999; 43:252-7.

Witsell DL, Drake AF, Warren DW. Preliminary data on the effect of pharyngeal flaps on the upper airway in children whith velopharyngeal inadequacy. Laryngoscope 1994; 104:12-5.

Witzel MA. Communicative impairment associated with clefting. In: Shprintzen RJ, Bardach J. editors. Cleft palate speech management: a multidisciplinary approach St. Louis: Mosby-Year Book; 1995. p. 138-66.

Witt PD, D'Antonio LL. Velopharyngeal insufficiency and secondary palatal management: a new look at an old problem. Clin Plast Surg 1993; 20:707-21.

Yamashita RP. Estudo da pressão aérea intra-oral na fala de indivíduos com fissura palatina congênita [dissertação]. São Paulo: Pontificia Universidade Católica de São Paulo; 1990.

Ysunza A, Garcia-Velasco M, Garcia-Garcia M, Haro R, Valencia M. Obstructive sleep apnea secondary to surgery for velopharyngeal insufficiency. Cleft Palate Craniofac J 1993; 4:387-90.

Zar JH. Biostatistical Analysis. 3rd.ed. New Jersey: Prentice-Hall; 1996. 
Zuiani TBB. Efeitos do tratamento cirúrgico da inadequação velofaringea sobre a ressonância da fala: análise perceptiva e nasométrica [dissertação]. São Paulo: Pontifícia Universidade Católica de São Paulo; 1996.

Zuiani TBB, Trindade IEK, Yamashita RP, Trindade Junior AS. The pharyngeal flap surgery in patients with velopharyngeal insufficiency: perceptual and nasometric speech assessment. Braz J Dysmorphol Speech Dis 1998; 2:31-42. 
Anexos 
Anexo 1 
Tabela 1A - Grau de fechamento velofaringeo, segundo classificação de Warren (1997), avaliado durante a produção da plosiva /p/, determinado antes da cirurgia (PRE), na primeira (POS1) e na segunda avaliação pós-cirúrgica (POS2) nos grupos com queixas (CQ) e sem queixas respiratótias (SQ).

\begin{tabular}{|c|c|c|c|c|c|c|}
\hline & \multicolumn{3}{|c|}{ GRUPO CQ } & \multicolumn{3}{|c|}{ GRUPO SQ } \\
\hline & PRE & POS1 & POS2 & PRE & POS1 & POS2 \\
\hline 1 & I & I & I & gg & A & A \\
\hline 2 & I & - & A & A & A & A \\
\hline 3 & I & - & A & gg & gg & I \\
\hline 4 & I & A & A & I & I & I \\
\hline 5 & I & $\mathrm{M}$ & $\mathrm{M}$ & I & - & $\mathrm{M}$ \\
\hline 6 & I & $\mathrm{M}$ & A & $\mathrm{M}$ & A & A \\
\hline 7 & A & A & A & I & - & I \\
\hline 8 & I & I & I & I & I & I \\
\hline 9 & A & A & A & A & - & $\mathrm{A}$ \\
\hline 10 & A & A & A & gg & I & A \\
\hline 11 & I & gg & A & $\mathrm{M}$ & $\mathrm{A}$ & $\mathrm{A}$ \\
\hline 12 & A & A & A & I & A & A \\
\hline 13 & I & $\mathrm{M}$ & $\mathrm{M}$ & gg & $\mathrm{M}$ & $\mathrm{A}$ \\
\hline 14 & I & $\mathrm{M}$ & $\mathrm{M}$ & gg & A & A \\
\hline 15 & I & - & $\mathrm{M}$ & $\mathrm{M}$ & $\mathrm{M}$ & $\mathrm{M}$ \\
\hline 16 & I & A & $\mathrm{A}$ & A & A & A \\
\hline 17 & I & A & A & I & I & $\mathrm{M}$ \\
\hline 18 & I & - & $\mathrm{A}$ & $\mathrm{M}$ & A & A \\
\hline 19 & gg & I & A & I & I & I \\
\hline 20 & I & A & $\mathrm{A}$ & I & $\mathrm{A}$ & A \\
\hline 21 & gg & gg & A & gg & I & gg \\
\hline 22 & & & & gg & $\mathrm{A}$ & A \\
\hline 23 & & & & I & $\mathrm{M}$ & A \\
\hline 24 & & & & I & $\mathrm{A}$ & A \\
\hline 25 & & & & I & A & A \\
\hline 26 & & & & I & I & I \\
\hline 27 & & & & I & gg & A \\
\hline 28 & & & & I & A & $\mathrm{M}$ \\
\hline 29 & & & & gg & $\mathrm{A}$ & A \\
\hline 30 & & & & I & I & $\mathrm{M}$ \\
\hline 31 & & & & $\mathrm{~A}$ & $\mathrm{~A}$ & $\mathrm{~A}$ \\
\hline 32 & & & & $\mathrm{M}$ & $\mathrm{M}$ & A \\
\hline 33 & & & & gg & I & A \\
\hline 34 & & & & gg & A & A \\
\hline 35 & & & & A & A & A \\
\hline 36 & & & & gg & - & gg \\
\hline 37 & & & & A & A & A \\
\hline
\end{tabular}

$\mathrm{I}=$ Fechamento inadequado

$\mathrm{A}=$ Fechamento adequado

$\mathrm{M}=$ Fechamento marginal

gg = golpe de glote (medida de área não disponível) 
Anexo 2 
Anexo 2 - Parecer do comitê de ética em pesquisa do Hospital de

Reabilitação de Anomalias Craniofaciais - Universidade de São Paulo.

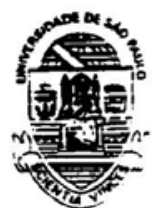

\author{
UNIVERSIDADE DE SÃO PAULO \\ HOSPITAL DE REABILTTAÇÃO DE ANOMALIAS CRANIOFACIAIS

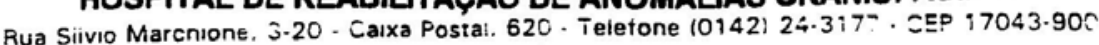 \\ BAURU - S.P. - Brasil
}

Of. $N^{C}$ 74/98-CEP-UEP

Bauru, 17 de novembro de 1998.

Prezada Senhora

Comunicamos que em reunião do Comitê de Ética em Pesquisa realizada em $28 / 10 / 98$, o projeto de pesquisa abaixo:

Título: Dimensões das vias aéreas nasais antes e após a cirurgia de retalho faringeo em pacientes com insuficiência velofaríngea.

Pesquisadora: Renata Paciello Yamashita

Curso: Doutorado

Após análise, o projeto de pesquisa foi aprovado, pois o mesmo enquadra-se dentro dos princípios de ética que orientam as pesquisas em seres humanos.

Atenciosamente

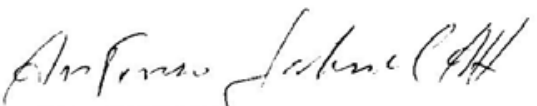

PROF. DR. ANTONIO GABRIEL ATTA

Presidente do Comitê de Ética em Pesquisa

IIma. Sra

Profa. Dra. INGE ELLY KIEMLE TRINDADE

DD. Presidente da Comissão de Pós-Graduação do HRACF-USP 
Anexo 3 
Quadro 1A - Questionário aplicado para o levantamento de queixas respiratórias.

\section{HRAC - USP \\ SETOR DE FISIOLOGIA}

\section{QUESTIONÁRIO DE SINTOMAS RESPIRATÓRIOS}

(Caouette-Laberge et al. Cleft Palate-Craniofac J 29:27, 1992.)

Nome:

RGs:

Doença respiratória

Obstrução nasal

(dificuldade em respirar pelo nariz)

Respiração bucal

Secreção nasal

Uso de descongestionantes nasais

Dificuldade em assoprar o nariz

Resfriados freqüentes

Secreção na garganta

Falta de ar

Dificuldade respiratória no exercício (a ponto de impedir as atividades)

Dificuldades para dormir

(a ponto de incomodar os outros)

Obstrução respiratória no sono

Perda de olfato

Sonolência

Cansaço constante

Problemas de concentração

Perda de energia, apetite ou peso

Náusea e vômito

Fumo

Outras: 
Anexo 4 
Quadro 2A - Dados normativos da área de secção transversa mínima nasal aferida por rinomanometria posterior (ANp), em $\mathrm{cm}^{2}$, em função da idade.

\begin{tabular}{|cccc|}
\hline \multirow{2}{*}{$\begin{array}{c}\text { Idade } \\
\text { (anos) }\end{array}$} & $\begin{array}{c}\text { ÁREA NASAL (cm }{ }^{2} \text { ) } \\
\text { (valores médios) }\end{array}$ & $\begin{array}{c}\text { Reduzida } \\
\text { (valores limites) }\end{array}$ & $\begin{array}{c}\text { Moderada a } \\
\text { gravemente } \\
\text { reduzida } \\
\text { (valores limites) }\end{array}$ \\
\cline { 2 - 4 } 6 & 0.21 & 0.14 & 0.10 \\
7 & 0.24 & 0.17 & 0.12 \\
8 & 0.32 & 0.21 & 0.16 \\
9 & 0.35 & 0.23 & 0.17 \\
10 & 0.36 & 0.24 & 0.18 \\
11 & 0.38 & 0.25 & 0.19 \\
12 & 0.41 & 0.27 & 0.20 \\
13 & 0.44 & 0.29 & 0.22 \\
14 & 0.47 & 0.31 & 0.24 \\
15 & 0.50 & 0.33 & 0.25 \\
16 & 0.53 & 0.35 & 0.27 \\
17 & 0.56 & 0.37 & 0.28 \\
\hline 18 & 0.60 & 0.40 ou 0.40 & 0.30 \\
\hline
\end{tabular}

FONTE: Dalston RM, Warren DW, Dalston ET. A preliminary study of nasal airway patency and its potential effect on speech performance. Cleft Palate Craniofac J 1992; 29:330-5.

Warren DW: comunicação pessoal. 
Quadro 3A - Valores individuais da área de secção transversa mínima nasofaríngea (ANF), em $\mathrm{cm}^{2}$, em indivíduos normais.

\begin{tabular}{|c|c|c|}
\hline Paciente & Idade & ÁREA NASOFARÍNGEA \\
\hline 1 & 6 & $>0,800$ \\
\hline 2 & 6 & 0,647 \\
\hline 3 & 6 & $>0,800$ \\
\hline 4 & 6 & $>0,800$ \\
\hline 5 & 7 & $>0,800$ \\
\hline 6 & 7 & $>0,800$ \\
\hline 7 & 7 & $>0,800$ \\
\hline 8 & 7 & $>0,800$ \\
\hline 9 & 8 & 0,618 \\
\hline 10 & 8 & $>0,800$ \\
\hline 11 & 8 & $>0,800$ \\
\hline 12 & 8 & $>0,800$ \\
\hline 13 & 9 & $>0,800$ \\
\hline 14 & 9 & 0,767 \\
\hline 15 & 9 & $>0,800$ \\
\hline 16 & 9 & $>0,800$ \\
\hline 17 & 10 & $>0,800$ \\
\hline 18 & 10 & $>0,800$ \\
\hline 19 & 10 & $>0,800$ \\
\hline 20 & 10 & $>0,800$ \\
\hline 21 & 18 & 0,570 \\
\hline 22 & 18 & $>0,800$ \\
\hline 23 & 18 & $>0,800$ \\
\hline 24 & 19 & $>0,800$ \\
\hline 25 & 20 & $>0,800$ \\
\hline 26 & 21 & 0,721 \\
\hline 27 & 22 & $>0,800$ \\
\hline 28 & 23 & $>0,800$ \\
\hline 29 & 23 & $>0,800$ \\
\hline 30 & 24 & $>0,800$ \\
\hline 31 & 25 & $>0,800$ \\
\hline 32 & 27 & $>0,800$ \\
\hline 33 & 28 & $>0,800$ \\
\hline 34 & 28 & $>0,800$ \\
\hline 35 & 29 & $>0,800$ \\
\hline 36 & 31 & $>0,800$ \\
\hline 37 & 31 & $>0,800$ \\
\hline 38 & 31 & $>0,800$ \\
\hline 39 & 33 & $>0,800$ \\
\hline 40 & 33 & $>0,800$ \\
\hline
\end{tabular}

FONTE: Sampaio ACM, Trindade IEK, Genaro KF, Yamashita RP, Trindade Jr, AS. Dimensões das vias aéreas na respiração de repouso: áreas nasal e nasofaríngea. In: Livro de Resumos do I Congresso científico da pós-graduação do HPRLLP - USP; 1997 nov 28-29; Bauru, Brasil. São Paulo; 1997. p. 31. 
Anexo 5 
Tabela 2A - Queixas respiratórias relatadas pelos pacientes na primeira (POS1) e na segunda avaliação pós-cirúrgica (POS2), nos grupos com queixas (CQ) e sem queixas respiratórias (SQ).

\begin{tabular}{|c|c|c|c|c|c|}
\hline \multirow[b]{3}{*}{ Paciente } & \multicolumn{5}{|c|}{ QUEIXAS RESPIRATÓRIAS } \\
\hline & \multicolumn{2}{|c|}{ Grupo CQ } & \multirow[b]{2}{*}{ Paciente } & \multicolumn{2}{|c|}{ Grupo SQ } \\
\hline & POS1 & POS2 & & POS1 & POS2 \\
\hline 1 & 2 & 2 & 22 & 0 & 0 \\
\hline 2 & - & 1 & 23 & 2 & 0 \\
\hline 3 & 1 & 1 & 24 & 3 & 0 \\
\hline 4 & 1 & $1+2$ & 25 & 0 & 0 \\
\hline 5 & 2 & 2 & 26 & - & 0 \\
\hline 6 & 2 & 2 & 27 & 2 & 0 \\
\hline 7 & 2 & $1+2$ & 28 & - & 0 \\
\hline 8 & 2 & 2 & 29 & 0 & 0 \\
\hline 9 & 2 & 2 & 30 & - & 0 \\
\hline 10 & 2 & 2 & 31 & 0 & 0 \\
\hline 11 & 2 & 2 & 32 & 0 & 0 \\
\hline 12 & 2 & 2 & 33 & 2 & 0 \\
\hline 13 & 2 & 2 & 34 & 0 & 0 \\
\hline 14 & 2 & 2 & 35 & 0 & 0 \\
\hline 15 & - & 2 & 36 & 0 & 0 \\
\hline 16 & $1+2+3$ & 2 & 37 & 0 & 0 \\
\hline 17 & 2 & 2 & 38 & 0 & 0 \\
\hline 18 & - & 1 & 39 & 0 & 0 \\
\hline 19 & 2 & 2 & 40 & 0 & 0 \\
\hline 20 & 2 & 2 & 41 & 1 & 0 \\
\hline \multirow[t]{17}{*}{21} & 1 & 1 & 42 & 2 & 0 \\
\hline & & & 43 & 0 & 0 \\
\hline & & & 44 & 0 & 0 \\
\hline & & & 45 & 2 & 0 \\
\hline & & & 46 & 0 & 0 \\
\hline & & & 47 & 0 & 0 \\
\hline & & & 48 & 1 & 0 \\
\hline & & & 49 & 0 & 0 \\
\hline & & & 50 & 3 & 0 \\
\hline & & & 51 & 0 & 0 \\
\hline & & & 52 & 0 & 0 \\
\hline & & & 53 & 0 & 0 \\
\hline & & & 54 & 0 & 0 \\
\hline & & & 55 & 0 & 0 \\
\hline & & & 56 & 0 & 0 \\
\hline & & & 57 & - & 0 \\
\hline & & & 58 & 2 & 0 \\
\hline
\end{tabular}

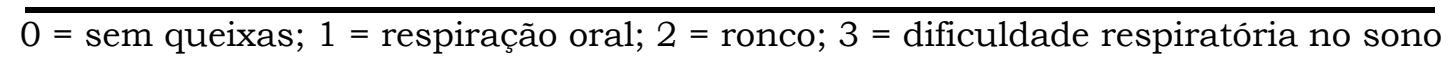


Tabela 3A - Valores individuais e médios da área de secção transversa mínima nasal, determinados por rinomanometria posterior (ANp), expressos em $\mathrm{cm}^{2}$, obtidos antes da cirurgia (PRE), na primeira (POS1) e na segunda avaliação póscirúrgica (POS2) e as diferenças entre os valores pré e pós-cirúrgicos, no grupo com queixas respiratórias (CQ).

\begin{tabular}{|c|c|c|c|c|c|}
\hline & \multicolumn{2}{|c|}{$\mathbf{A N p}$} & \multirow[b]{2}{*}{ POS2 } & \multicolumn{2}{|c|}{ DIFERENÇAS } \\
\hline & PRE & POS1 & & POS1 - PRE & POS2 - PRE \\
\hline 1 & 0,686 & 0,399 & 0,345 & $-0,287 \#$ & $-0,341 \#$ \\
\hline 2 & 0,470 & - & 0,415 & - & $-0,055 \#$ \\
\hline 3 & 0,438 & $0,000^{*}$ & $0,000^{*}$ & $-0,438 \#$ & $-0,438 \#$ \\
\hline 4 & $0,377^{*}$ & - & $0,009 *$ & - & $-0,368 \#$ \\
\hline 5 & 0,448 & $0,399 *$ & 0,442 & $-0,049 \#$ & $-0,006$ \\
\hline 6 & 0,580 & 0,491 & 0,492 & $-0,089 \#$ & $-0,088 \#$ \\
\hline 7 & 0,394 & 0,387 & 0,280 & $-0,007$ & $-0,114 \#$ \\
\hline 8 & 0,420 & 0,349 & $0,252^{*}$ & $-0,071 \#$ & $-0,168 \#$ \\
\hline 9 & 0,582 & 0,395 & 0,461 & $-0,187 \#$ & $-0,121 \#$ \\
\hline 10 & 0,407 & 0,264 & 0,327 & $-0,143 \#$ & $-0,080 \#$ \\
\hline 11 & 0,404 & 0,482 & 0,363 & $+0,078 \#$ & $-0,041 \#$ \\
\hline 12 & 0,375 & $0,229 *$ & 0,268 & $-0,146 \#$ & $-0,107 \#$ \\
\hline 13 & 0,496 & 0,365 & 0,574 & $-0,131 \#$ & $+0,078 \#$ \\
\hline 14 & 0,486 & 0,449 & 0,685 & $-0,037$ & $+0,199 \#$ \\
\hline 15 & 0,555 & - & $0,273^{*}$ & - & $-0,282 \#$ \\
\hline 16 & 0,624 & 0,410 & 0,445 & $-0,214 \#$ & $-0,179 \#$ \\
\hline 17 & $0,128^{*}$ & 0,280 & $0,221^{*}$ & $+0,152 \#$ & $+0,093 \#$ \\
\hline 18 & 0,313 & - & 0,257 & - & $-0,056 \#$ \\
\hline 19 & 0,376 & $0,306^{*}$ & $0,224^{*}$ & $-0,070 \#$ & $-0,152 \#$ \\
\hline 20 & 0,433 & 0,317 & $0,171^{*}$ & $-0,116 \#$ & $-0,262 \#$ \\
\hline 21 & 0,768 & 0,826 & 0,522 & $+0,058$ & $-0,246 \#$ \\
\hline $\bar{X}$ & 0,465 & 0,373 & 0,335 & $-0,100$ & $-0,130$ \\
\hline$\pm \mathrm{DP}$ & 0,138 & 0,164 & 0,170 & 0,140 & 0,157 \\
\hline
\end{tabular}

* valores subnormais de acordo com Dalston et al (1992)

\# variações significativas (>10\% do valor observado no pré-operatório) 
Tabela 4A - Valores individuais e médios da área de secção transversa mínima nasal determinados por rinomanometria posterior (ANp), expressos em $\mathrm{cm}^{2}$, obtidos antes da cirurgia (PRE), na primeira (POS1) e na segunda avaliação pós-cirúrgica (POS2) e as diferenças entre os valores pré e pós-cirúrgicos, no grupo sem queixas respiratórias (SQ).

\begin{tabular}{clllcc}
\hline & \multicolumn{3}{c}{ ANp } & \multicolumn{2}{c}{ DIFERENÇAS } \\
\cline { 2 - 6 } & PRE & POS1 & POS2 & POS1-PRE & POS2-PRE \\
\hline 1 & 0,536 & 0,277 & 0,544 & $-0,259 \#$ & $+0,008$ \\
2 & 0,475 & 0,445 & 0,586 & $-0,030$ & $+0,111 \#$ \\
3 & 0,609 & 0,581 & 0,800 & $-0,028$ & $+0,191 \#$ \\
4 & 0,401 & 0,553 & 0,631 & $+0,152 \#$ & $+0,230 \#$ \\
5 & 0,382 & - & 0,292 & - & $-0,090 \#$ \\
6 & 0,388 & 0,385 & 0,439 & $-0,003$ & $+0,051 \#$ \\
7 & 0,664 & - & 0,699 & - & $+0,035$ \\
8 & 0,477 & $0,391^{*}$ & $0,365^{*}$ & $-0,086 \#$ & $-0,112 \#$ \\
9 & 0,598 & - & 0,478 & - & $-0,120 \#$ \\
10 & 0,800 & 0,800 & 0,757 & 0,000 & $-0,043$ \\
11 & 0,818 & 0,525 & 0,589 & $-0,293 \#$ & $-0,229 \#$ \\
12 & 0,345 & $0,153^{*}$ & $0,174^{*}$ & $-0,192 \#$ & $-0,171 \#$ \\
13 & 0,512 & $0,338^{*}$ & $0,301^{*}$ & $-0,174 \#$ & $-0,211 \#$ \\
14 & 0,682 & 0,398 & 0,608 & $-0,284 \#$ & $-0,074 \#$ \\
15 & 0,520 & 0,530 & $0,398^{*}$ & $+0,010$ & $-0,122 \#$ \\
16 & 0,330 & 0,371 & 0,313 & $+0,041 \#$ & $-0,017$ \\
17 & 0,404 & $0,316^{*}$ & $0,288^{*}$ & $-0,088 \#$ & $-0,116 \#$ \\
18 & $0,241^{*}$ & $0,268^{*}$ & $0,179^{*}$ & $+0,027 \#$ & $-0,062 \#$ \\
19 & 0,783 & 0,620 & 0,490 & $-0,163 \#$ & $-0,293 \#$ \\
20 & 0,614 & 0,446 & $0,302^{*}$ & $-0,168 \#$ & $-0,312 \#$ \\
21 & 0,413 & $0,289^{*}$ & $0,300^{*}$ & $-0,124$ & $-0,113 \#$ \\
22 & 0,463 & 0,497 & 0,468 & $+0,034$ & $+0,005$ \\
23 & 0,879 & 0,505 & 0,639 & $-0,374 \#$ & $-0,240 \#$ \\
24 & 0,776 & 0,646 & 0,867 & $-0,130 \#$ & $+0,091 \#$ \\
25 & 0,389 & $0,295^{*}$ & $0,388^{*}$ & $-0,094 \#$ & $-0,001$ \\
26 & $0,365^{*}$ & 0,418 & 0,430 & $+0,053 \#$ & $+0,065 \#$ \\
27 & 0,332 & 0,474 & $0,314 *$ & $+0,142 \#$ & $-0,018$ \\
28 & $0,379^{*}$ & $0,294^{*}$ & $0,329^{*}$ & $-0,085 \#$ & $-0,050 \#$ \\
29 & 0,826 & 0,439 & 0,554 & $-0,387 \#$ & $-0,272 \#$ \\
30 & 0,751 & 0,417 & 0,524 & $-0,334 \#$ & $-0,227 \#$ \\
31 & 0,470 & 0,414 & 0,498 & $-0,056 \#$ & $+0,028$ \\
32 & 0,399 & $0,265^{*}$ & 0,512 & $-0,134 \#$ & $+0,113 \#$ \\
33 & 0,553 & 0,468 & 0,694 & $-0,085 \#$ & $+0,141 \#$ \\
34 & $0,304^{*}$ & $0,379^{*}$ & $0,234^{*}$ & $+0,075 \#$ & $-0,070 \#$ \\
35 & 0,676 & 0,433 & $0,170^{*}$ & $-0,243 \#$ & $-0,506 \#$ \\
36 & $0,360^{*}$ & - & $0,250^{*}$ & - & $-0,110 \#$ \\
37 & 0,434 & 0,747 & 0,641 & $+0,313 \#$ & $+0,207 \#$ \\
\hline $\mathrm{X}$ & 0,523 & 0,436 & 0,461 & $-0,090$ & $-0,062$ \\
$\pm \mathrm{D}$ & 0,174 & 0,141 & 0,183 & 0,158 & 0,159 \\
\hline & & & & &
\end{tabular}

* valores subnormais de acordo com Dalston et al (1992)

\# variações significativas (>10\% do valor observado no pré-operatório) 
Tabela 5A - Valores individuais da área de secção transversa mínima nasofaríngea, determinados por rinomanometria anterior modificada (ANF), expressos $\mathrm{em} \mathrm{cm}^{2}$, obtidos antes da cirurgia (PRE), na primeira (POS1) e na segunda avaliação póscirúrgica (POS2) e as diferenças entre os valores pré e pós-cirúrgicos, no grupo com queixas respiratórias (CQ).

\begin{tabular}{cccccc}
\hline & \multicolumn{3}{c}{ ANF } & & \multicolumn{2}{c}{ DIFERENÇAS } \\
\cline { 2 - 6 } & PRE & POS1 & POS2 & POS1-PRE & POS2-PRE \\
\hline 1 & 0,800 & 0,502 & $0,460^{*}$ & $-0,298 \#$ & $-0,340 \#$ \\
2 & 0,800 & - & 0,571 & - & $-0,229 \#$ \\
3 & 0,553 & $0,011^{*}$ & $0,000^{*}$ & $-0,542 \#$ & $-0,553 \#$ \\
4 & 0,800 & - & $0,000^{*}$ & - & $-0,800 \#$ \\
5 & 0,800 & $0,492^{*}$ & 0,571 & $-0,308 \#$ & $-0,229 \#$ \\
6 & 0,800 & 0,800 & 0,800 & 0,000 & 0,000 \\
7 & 0,800 & 0,800 & 0,800 & 0,000 & 0,000 \\
8 & 0,800 & 0,508 & 0,800 & $-0,292 \#$ & 0,000 \\
9 & 0,800 & $0,443^{*}$ & 0,505 & $-0,357 \#$ & $-0,295 \#$ \\
10 & 0,800 & $0,166^{*}$ & $0,278^{*}$ & $-0,634 \#$ & $-0,522 \#$ \\
11 & 0,800 & $0,459^{*}$ & 0,740 & $-0,341 \#$ & $-0,060$ \\
12 & 0,800 & $0,301^{*}$ & $0,340 *$ & $-0,499 \#$ & $-0,460 \#$ \\
13 & 0,800 & 0,621 & 0,690 & $-0,179 \#$ & $-0,110 \#$ \\
14 & 0,800 & 0,800 & 0,800 & 0,000 & 0,000 \\
15 & 0,800 & - & 0,676 & & $-0,124 \#$ \\
16 & 0,800 & $0,487^{*}$ & 0,589 & $-0,313 \#$ & $-0,211 \#$ \\
17 & 0,800 & $0,388^{*}$ & 0,800 & $-0,412 \#$ & 0,000 \\
18 & 0,800 & - & 0,599 & & $-0,201 \#$ \\
19 & 0,800 & $0,476^{*}$ & $0,252^{*}$ & $-0,324 \#$ & $-0,548 \#$ \\
20 & 0,800 & $0,328^{*}$ & $0,188^{*}$ & $-0,472 \#$ & $-0,612 \#$ \\
21 & 0,800 & 0,583 & 0,795 & $-0,217 \#$ & $-0,005$ \\
\hline
\end{tabular}

*valores subnormais

\# variações significativas (>10\% do valor observado no pré-operatório) 
Tabela 6A - Valores individuais da área de secção transversa mínima nasofaríngea, determinados por rinomanometria anterior modificada (ANF), expressos $\mathrm{em} \mathrm{cm}^{2}$, obtidos antes da cirurgia (PRE), na primeira (POS1) e na segunda avaliação póscirúrgica (POS2) e as diferenças entre os valores pré e pós-cirúrgicos, no grupo sem queixas respiratórias (SQ).

\begin{tabular}{|c|c|c|c|c|c|}
\hline & \multicolumn{3}{|c|}{ ANF } & \multicolumn{2}{|c|}{ DIFERENÇAS } \\
\hline & PRE & POS1 & POS2 & POS1-PRE & POS2-PRE \\
\hline 1 & 0,800 & 0,680 & 0,800 & $-0,120 \#$ & 0,000 \\
\hline 2 & 0,800 & 0,797 & 0,800 & $-0,003$ & 0,000 \\
\hline 3 & 0,800 & 0,738 & 0,800 & $-0,062$ & 0,000 \\
\hline 4 & 0,800 & 0,800 & 0,757 & 0,000 & $-0,043$ \\
\hline 5 & 0,800 & - & 0,799 & - & $-0,001$ \\
\hline 6 & 0,800 & 0,797 & 0,707 & $-0,003$ & -0,093\# \\
\hline 7 & 0,800 & - & 0,800 & - & 0,000 \\
\hline 8 & 0,800 & 0,744 & 0,800 & $-0,056$ & 0,000 \\
\hline 9 & 0,800 & - & $0,347^{*}$ & - & $-0,453 \#$ \\
\hline 10 & 0,800 & 0,800 & 0,800 & 0,000 & 0,000 \\
\hline 11 & 0,800 & 0,569 & 0,800 & $-0,231 \#$ & 0,000 \\
\hline 12 & 0,800 & 0,800 & 0,800 & 0,000 & 0,000 \\
\hline 13 & 0,800 & $0,252^{*}$ & $0,279^{*}$ & $-0,548 \#$ & $-0,521 \#$ \\
\hline 14 & 0,800 & 0,623 & 0,800 & $-0,177 \#$ & 0,000 \\
\hline 15 & 0,800 & $0,461^{*}$ & 0,684 & $-0,339 \#$ & $-0,116 \#$ \\
\hline 16 & 0,800 & 0,590 & 0,589 & $-0,210 \#$ & $-0,211 \#$ \\
\hline 17 & 0,800 & 0,780 & 0,800 & $-0,020$ & 0,000 \\
\hline 18 & 0,800 & $0,325^{*}$ & $0,186^{*}$ & $-0,475 \#$ & $-0,614 \#$ \\
\hline 19 & 0,800 & 0,800 & 0,800 & 0,000 & 0,000 \\
\hline 20 & 0,800 & 0,611 & 0,593 & $-0,189 \#$ & $-0,207 \#$ \\
\hline 21 & 0,800 & 0,800 & 0,800 & 0,000 & 0,000 \\
\hline 22 & 0,800 & 0,750 & 0,724 & $-0,050$ & $-0,076$ \\
\hline 23 & 0,800 & 0,667 & 0,800 & $-0,133 \#$ & 0,000 \\
\hline 24 & 0,800 & 0,800 & 0,800 & 0,000 & 0,000 \\
\hline 25 & 0,800 & 0,800 & 0,713 & 0,000 & $-0,087 \#$ \\
\hline 26 & 0,800 & $0,257^{*}$ & 0,800 & $-0,543 \#$ & 0,000 \\
\hline 27 & 0,800 & $0,442^{*}$ & 0,577 & $-0,358 \#$ & $-0,223 \#$ \\
\hline 28 & 0,800 & 0,578 & $0,467 *$ & $-0,222 \#$ & $-0,333 \#$ \\
\hline 29 & 0,800 & 0,671 & 0,573 & $-0,129 \#$ & $-0,227 \#$ \\
\hline 30 & 0,800 & $0,455^{*}$ & $0,474 *$ & $-0,345 \#$ & $-0,326 \#$ \\
\hline 31 & 0,800 & $0,413^{*}$ & 0,575 & $-0,387 \#$ & $-0,225 \#$ \\
\hline 32 & 0,800 & 0,620 & 0,547 & $-0,180 \#$ & $-0,253 \#$ \\
\hline 33 & 0,800 & 0,800 & 0,800 & 0,000 & 0,000 \\
\hline 34 & 0,800 & 0,800 & 0,800 & 0,000 & 0,000 \\
\hline 35 & 0,800 & $0,441^{*}$ & $0,451^{*}$ & $-0,359 \#$ & $-0,349 \#$ \\
\hline 36 & 0,800 & - & 0,800 & - & 0,000 \\
\hline 37 & 0,800 & 0,779 & 0,800 & $-0,021$ & 0,000 \\
\hline
\end{tabular}

* valores subnormais

\# variações significativas (>10\% do valor observado no pré-operatório) 
Tabela 7A - Valores individuais e médios da área de secção transversa mínima nasal, determinados por rinomanometria anterior ( $\mathrm{ANa}$ ), expressos em $\mathrm{cm}^{2}$, obtidos antes da cirurgia (PRE), na primeira (POS1) e na segunda avaliação pós-cirúrgica (POS2) e as diferenças entre os valores pré e pós-cirúrgicos, no grupo sem queixas respiratórias $(\mathrm{CQ})$.

\begin{tabular}{cccccc}
\hline & & ANa & & \multicolumn{2}{c}{ DIFERENÇAS } \\
\cline { 2 - 6 } & PRE & POS1 & POS2 & POS1-PRE & POS2-PRE \\
\hline 1 & 0,514 & 0,406 & 0,425 & $-0,108 \#$ & $-0,089 \#$ \\
2 & 0,499 & - & 0,369 & - & $-0,130 \#$ \\
3 & 0,387 & - & - & - & - \\
4 & 0,351 & - & - & - & - \\
5 & 0,410 & 0,393 & 0,611 & $-0,017$ & $+0,201 \#$ \\
6 & 0,594 & 0,559 & 0,634 & $-0,035$ & $+0,040$ \\
7 & 0,395 & 0,399 & 0,486 & $+0,004$ & $+0,091 \#$ \\
8 & 0,497 & 0,455 & 0,380 & $-0,042$ & $-0,117 \#$ \\
9 & 0,514 & 0,378 & 0,588 & $-0,136 \#$ & $+0,074 \#$ \\
10 & 0,478 & 0,345 & 0,504 & $-0,133 \#$ & $+0,026$ \\
11 & 0,421 & 0,448 & 0,468 & $+0,027$ & $+0,047 \#$ \\
12 & 0,303 & 0,415 & 0,423 & $+0,112 \#$ & $+0,120 \#$ \\
13 & 0,578 & 0,571 & 0,874 & $-0,007$ & $+0,296 \#$ \\
14 & 0,721 & 0,682 & 1,032 & $-0,039$ & $+0,311 \#$ \\
15 & 0,572 & - & 0,496 & - & $-0,076 \#$ \\
16 & 0,527 & 0,456 & 0,534 & $-0,071 \#$ & $+0,007$ \\
17 & 0,248 & 0,277 & 0,293 & $+0,029 \#$ & $+0,045 \#$ \\
18 & 0,328 & - & 0,268 & - & $-0,060 \#$ \\
19 & 0,279 & 0,579 & 0,311 & $+0,300 \#$ & $+0,032 \#$ \\
20 & 0,466 & 0,626 & 0,463 & $+0,160 \#$ & $-0,003$ \\
21 & 0,769 & 0,991 & 0,505 & $+0,222 \#$ & $0,264 \#$ \\
\hline $\mathrm{X}$ & 0,469 & 0,499 & 0,509 & $+0,017$ & $+0,029$ \\
$\pm \mathrm{DP}$ & 0,135 & 0,171 & 0,188 & 0,124 & 0,142 \\
\hline & & & & & \\
\hline
\end{tabular}

\# variações significativas (>10\% do valor observado no pré-operatório) 
Tabela 8A - Valores individuais e médios da área de secção transversa mínima nasal, determinados por rinomanometria anterior ( $\mathrm{ANa}$ ), expressos em $\mathrm{cm}^{2}$, obtidos antes da cirurgia (PRE), na primeira (POS1) e na segunda avaliação pós-cirúrgica (POS2) e as diferenças entre os valores pré e pós-cirúrgicos, no grupo sem queixas respiratórias (SQ).

\begin{tabular}{|c|c|c|c|c|c|}
\hline & \multicolumn{2}{|c|}{ ANa } & \multirow[b]{2}{*}{ POS2 } & \multicolumn{2}{|c|}{ DIFERENÇAS } \\
\hline & PRE & POS1 & & POS1-PRE & POS2-PRE \\
\hline 1 & 0,400 & 0,347 & 0,703 & $-0,053 \#$ & $+0,303 \#$ \\
\hline 2 & 0,528 & 0,559 & 0,592 & $+0,031$ & $+0,064 \#$ \\
\hline 3 & 0,762 & 0,762 & 0,870 & 0,000 & $+0,108 \#$ \\
\hline 4 & 0,571 & 0,610 & 0,873 & $+0,039$ & $+0,302 \#$ \\
\hline 5 & 0,456 & - & 0,384 & - & $-0,072 \#$ \\
\hline 6 & 0,509 & 0,506 & 0,583 & $-0,003$ & $+0,074 \#$ \\
\hline 7 & 0,553 & - & 0,890 & - & $+0,337 \#$ \\
\hline 8 & 0,636 & 0,366 & 0,492 & $-0,270 \#$ & $-0,144 \#$ \\
\hline 9 & 0,578 & - & 0,706 & - & $+0,128 \#$ \\
\hline 10 & 0,807 & 0,773 & 0,676 & $-0,034$ & $-0,131 \#$ \\
\hline 11 & 0,788 & 0,411 & 0,669 & $-0,377 \#$ & $-0,119 \#$ \\
\hline 12 & 0,376 & 0,147 & 0,299 & $-0,229 \#$ & $-0,077 \#$ \\
\hline 13 & 0,551 & 0,637 & 0,727 & $+0,086 \#$ & $+0,176 \#$ \\
\hline 14 & 0,833 & 0,676 & 0,542 & $-0,157 \#$ & $-0,291 \#$ \\
\hline 15 & 0,534 & 0,573 & 0,485 & $+0,039$ & $-0,049 \#$ \\
\hline 16 & 0,273 & 0,325 & 0,379 & $+0,052 \#$ & $+0,106 \#$ \\
\hline 17 & 0,652 & 0,405 & 0,590 & $-0,247 \#$ & $-0,062$ \\
\hline 18 & 0,236 & 0,442 & 0,305 & $+0,206 \#$ & $+0,069 \#$ \\
\hline 19 & 0,812 & 0,599 & 0,478 & $-0,213 \#$ & $-0,334 \#$ \\
\hline 20 & 0,481 & 0,559 & 0,376 & $+0,078 \#$ & $-0,105 \#$ \\
\hline 21 & 0,583 & 0,449 & 0,569 & $-0,134 \#$ & $-0,014$ \\
\hline 22 & 0,785 & 0,749 & 0,669 & $-0,036$ & $-0,116 \#$ \\
\hline 23 & 0,417 & 0,732 & 0,708 & $+0,315 \#$ & $+0,291 \#$ \\
\hline 24 & 0,820 & 0,661 & 1,014 & $-0,159 \#$ & $+0,194 \#$ \\
\hline 25 & 0,550 & 0,293 & 0,376 & $-0,257 \#$ & $-0,174 \#$ \\
\hline 26 & 0,338 & 0,449 & 0,780 & $+0,111 \#$ & $+0,442 \#$ \\
\hline 27 & 0,512 & 0,537 & 0,522 & $+0,025$ & $+0,010$ \\
\hline 28 & 0,437 & 0,477 & 0,324 & $+0,040$ & $-0,113 \#$ \\
\hline 29 & 0,872 & 0,767 & 0,757 & $-0,105 \#$ & $-0,115 \#$ \\
\hline 30 & 0,884 & 0,663 & 0,823 & $-0,221 \#$ & $-0,061$ \\
\hline 31 & 0,576 & 0,577 & 0,464 & $+0,001$ & $-0,112 \#$ \\
\hline 32 & 0,557 & 0,731 & 0,738 & $+0,174 \#$ & $+0,181 \#$ \\
\hline 33 & 0,521 & 0,600 & 0,926 & $+0,079 \#$ & $+0,405 \#$ \\
\hline 34 & 0,536 & 0,820 & 0,603 & $+0,284 \#$ & $+0,067 \#$ \\
\hline 35 & 0,694 & 0,617 & 0,172 & $-0,077 \#$ & $-0,522 \#$ \\
\hline 36 & 0,585 & - & 0,400 & - & $-0,185 \#$ \\
\hline 37 & 0,627 & 0,931 & 0,879 & $+0,304 \#$ & $+0,252 \#$ \\
\hline $\bar{X}$ & 0,585 & 0,568 & 0,604 & $-0,021$ & $+0,019$ \\
\hline$\pm \mathrm{DP}$ & 0,166 & 0,172 & 0,205 & 0,172 & 0,212 \\
\hline
\end{tabular}

\# variações significativas (>10\% do valor observado no pré-operatório) 